LA-UR- 08-3975

Approved for public release;

distribution is unlimited.
Title:

Author(s):

Intended for:
Preserving the Manhattan Project at Los Alamos--Oak Ridge's "Sister Secret City"

Ellen D. McGehee, LANL, ENV-EAQ

The Secret City Festival program at the American Museum of Science and Energy (AMSE), June 20, 2008

Los Alamos National Laboratory, an affirmative action/equal opportunity employer, is operated by the Los Alamos National Security, LLC for the National Nuclear Security Administration of the U.S. Department of Energy under contract DE-AC52-06NA25396. By acceptance of this article, the publisher recognizes that the U.S. Government retains a nonexclusive, royalty-free license to publish or reproduce the published form of this contribution, or to allow others to do so, for U.S. Government purposes. Los Alamos National Laboratory requests that the publisher identify this article as work performed under the auspices of the U.S. Department of Energy. Los Alamos National Laboratory strongly supports academic freedom and a researcher's right to publish; as an institution, however, the Laboratory does not endorse the viewpoint of a publication or guarantee its technical correctness.

Form $836(7 / 06)$ 
Abstract: Preserving the Manhattan Project at Los Alamos - Oak Ridge's "Sister Secret City"

A presentation given at Oak Ridge, Tennessee, as part of the Secret City Festival program at the American Museum of Science and Energy (AMSE).

At the June 20, 2008, 3:00 pm, "Sister Secret Cities" public program, Los Alamos National Laboratory (LANL) presenter Ellen McGehee will talk about the restoration of the Oppenheimer House and "V Site," where the Trinity device was assembled, as well as other LANL, Los Alamos County, and Los Alamos Historical Society historic preservation priorities. 


\section{Preserving the Manhattan Project at Los Alamos - Oak Ridge's "Sister Secret City"}

A presentation given at Oak Ridge, Tennessee, as part of the Secret City Festival program at the American Museum of Science and Energy (AMSE)

Ellen McGehee, Cultural Resources Team Leader

Los Alamos National Laboratory

June 20, 2008

- LosA 


\section{Oak Ridge - Uranium Production}

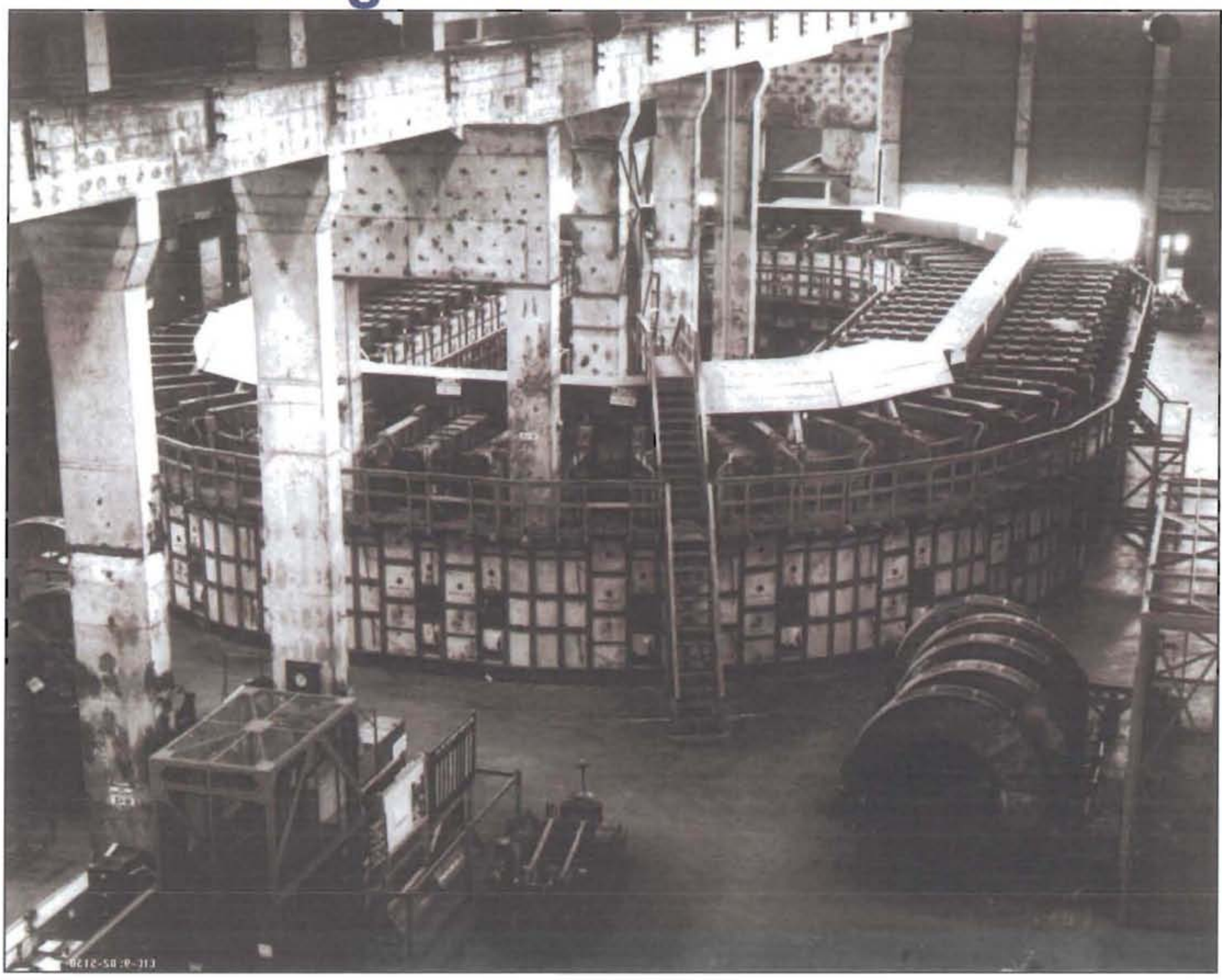




\section{Hanford - Plutonium Production}

3 Los Alamos

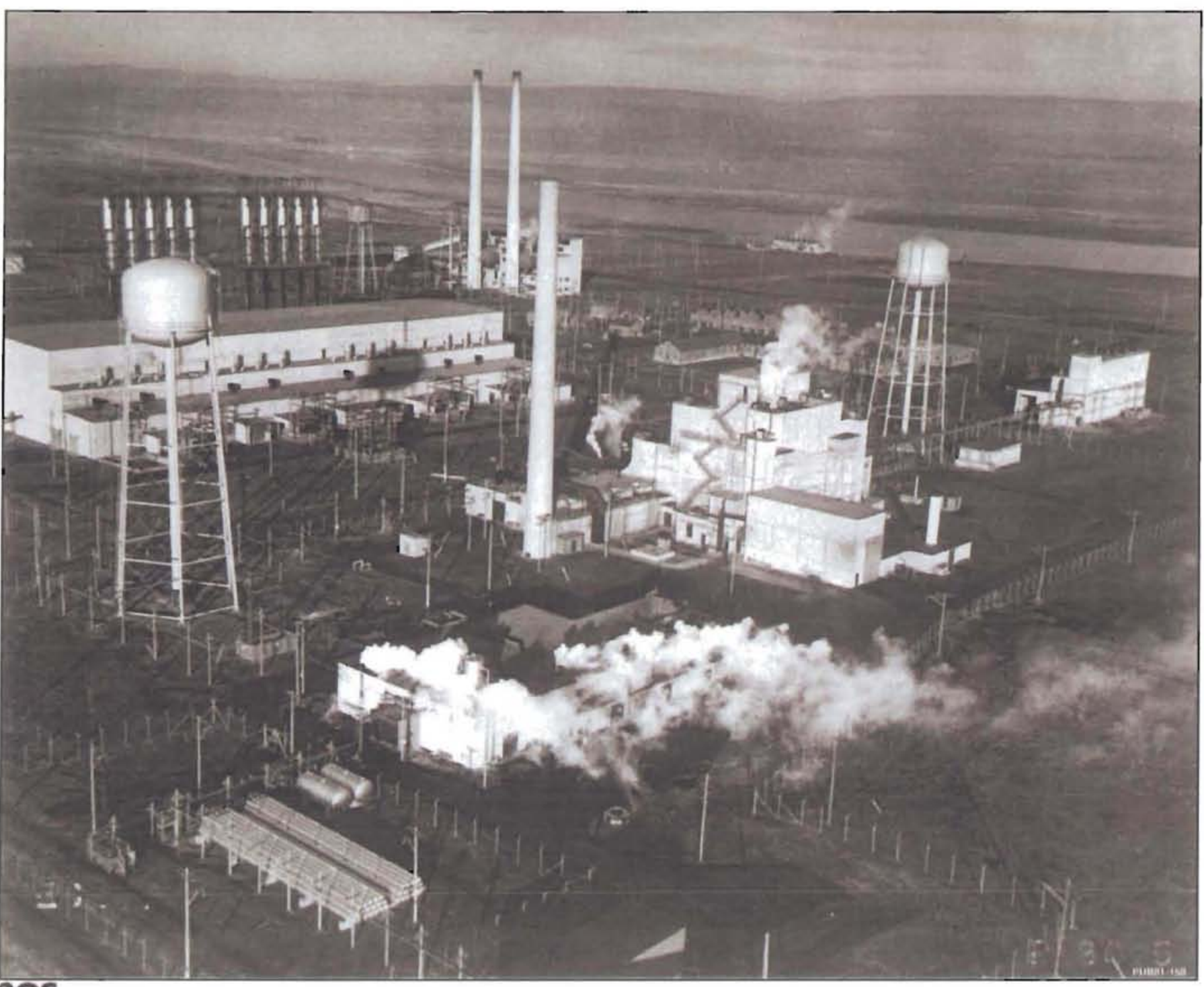




\section{Los Alamos - Weapons Design and Testing}

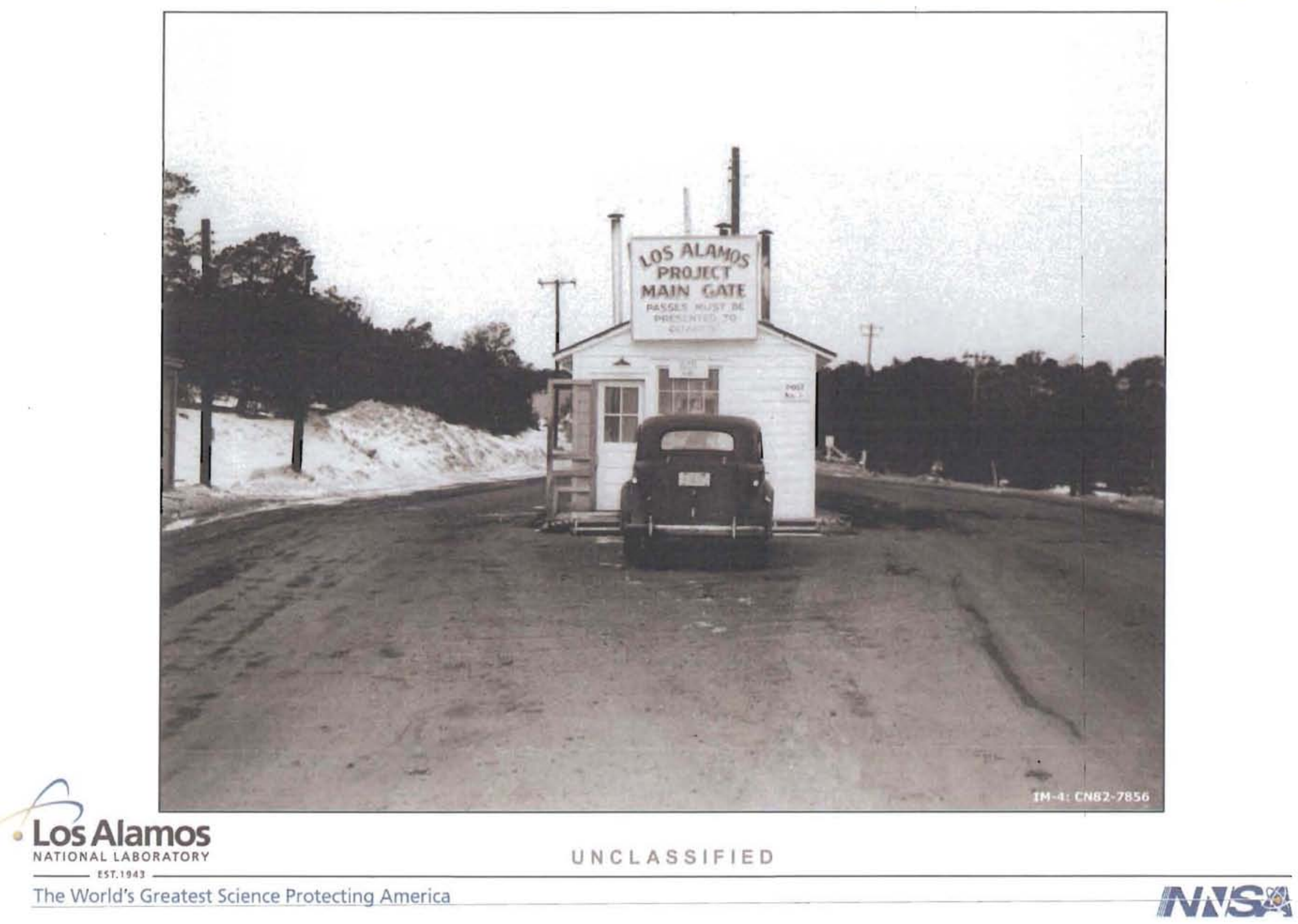




\section{The "Townsite" - Fuller Lodge and Bathtub Row}

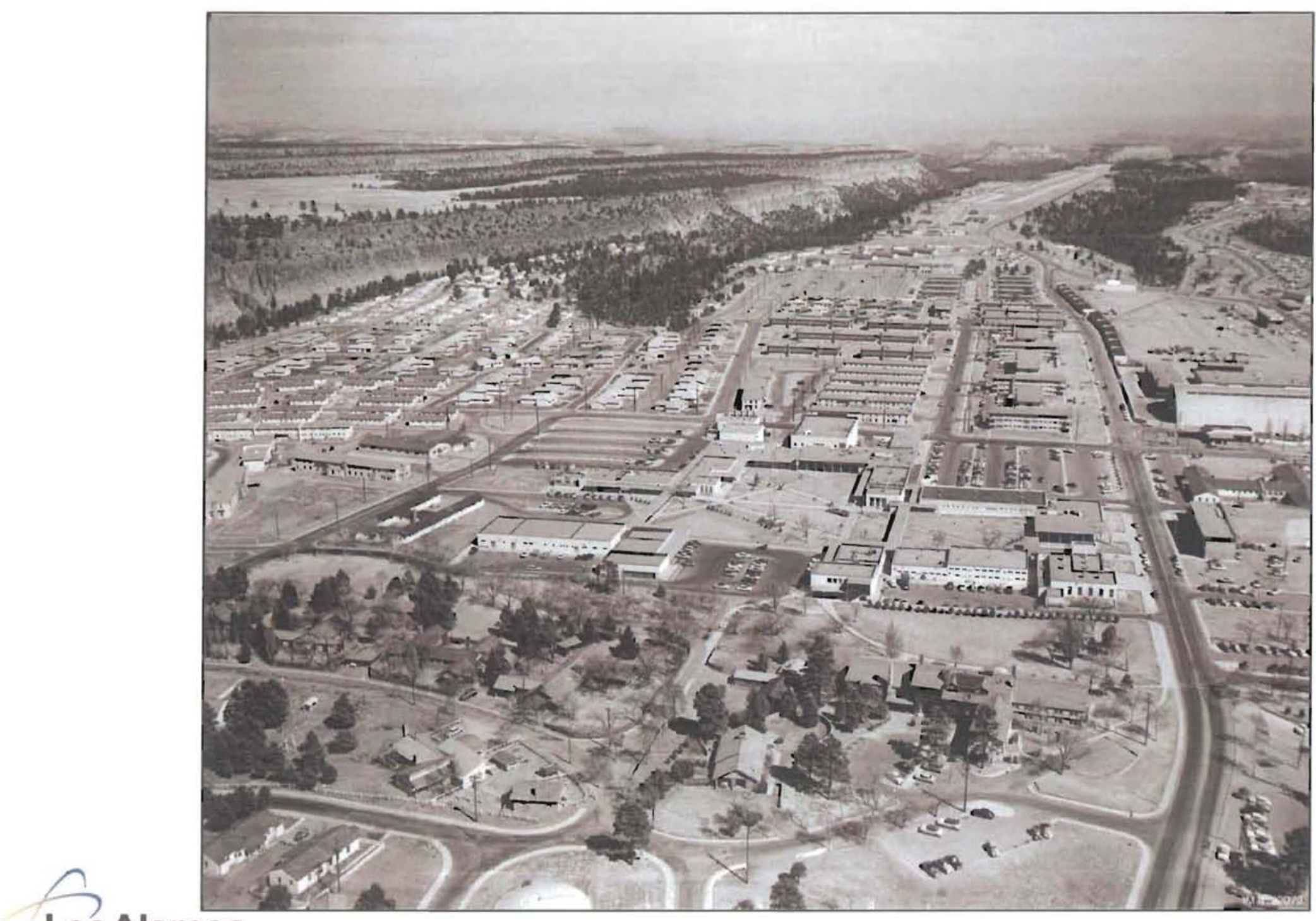

- Los Alamos NATIONAL LABORATORY

UNCLASSIFIED

The World's Greatest Science Protecting America

NASS 


\section{Los Alamos County}

Manhattan Project Historic Preservation Activities

- Ongoing restoration of Fuller Lodge (work on windows, door, and historic chinking)

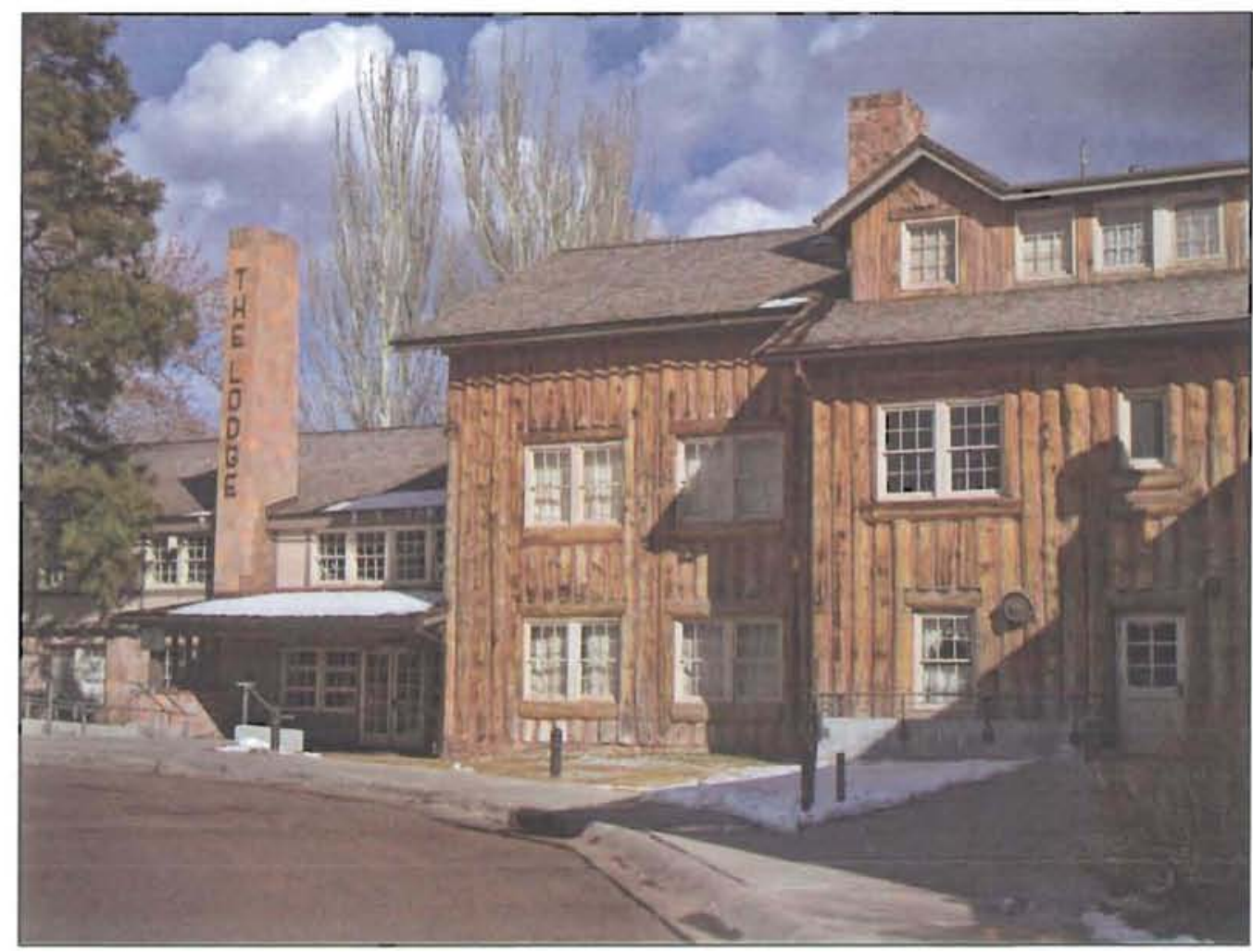




\section{Los Alamos County Manhattan Project Historic Preservation Activities}

- Bathtub Row Inventory

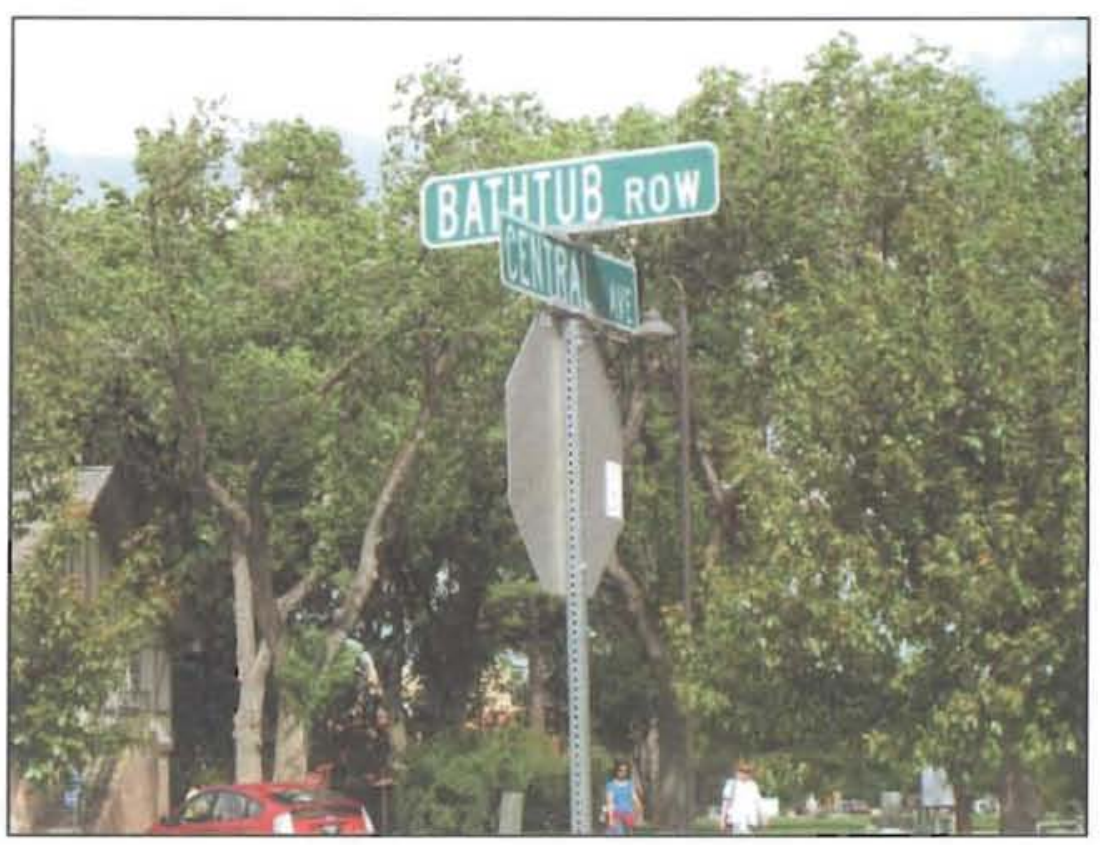

- Los Alamos NATIONAL LABORATORY

The World's Greatest Science Protecting America
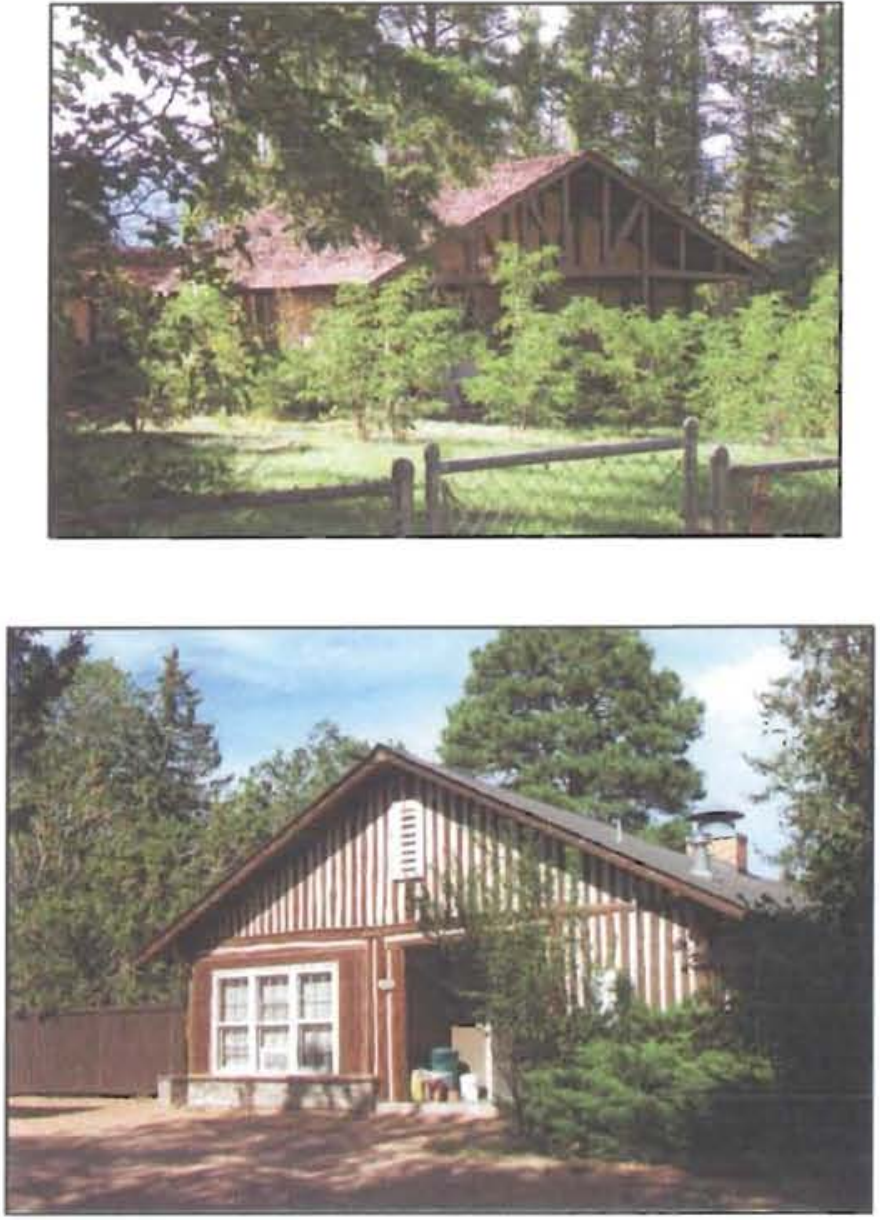

UNCLASSIFIED 


\section{Los Alamos Historical Society Manhattan Project Historic Preservation Activities}

- Oppenheimer House Restoration

Structural repairs were conducted to arrest the settling of the foundation.

Interior work included repairs to the kitchen ceiling from severe water damage. Damaged floor covering in the kitchen was replaced, and the bathroom tub and shower enclosure was repaired. The living room fireplace had interior damage that was repaired.

Exterior work included repairs to the chimney, skylights, stucco walls, log siding, and windows.

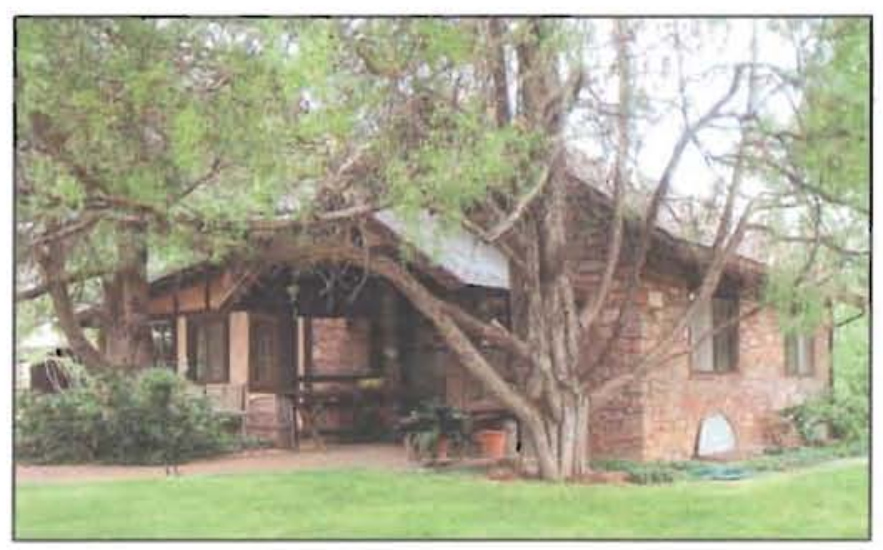


Los Alamos Historical Society Manhattan Project Historic Preservation Activities

- Oppenheimer House Restoration (Interior Views)

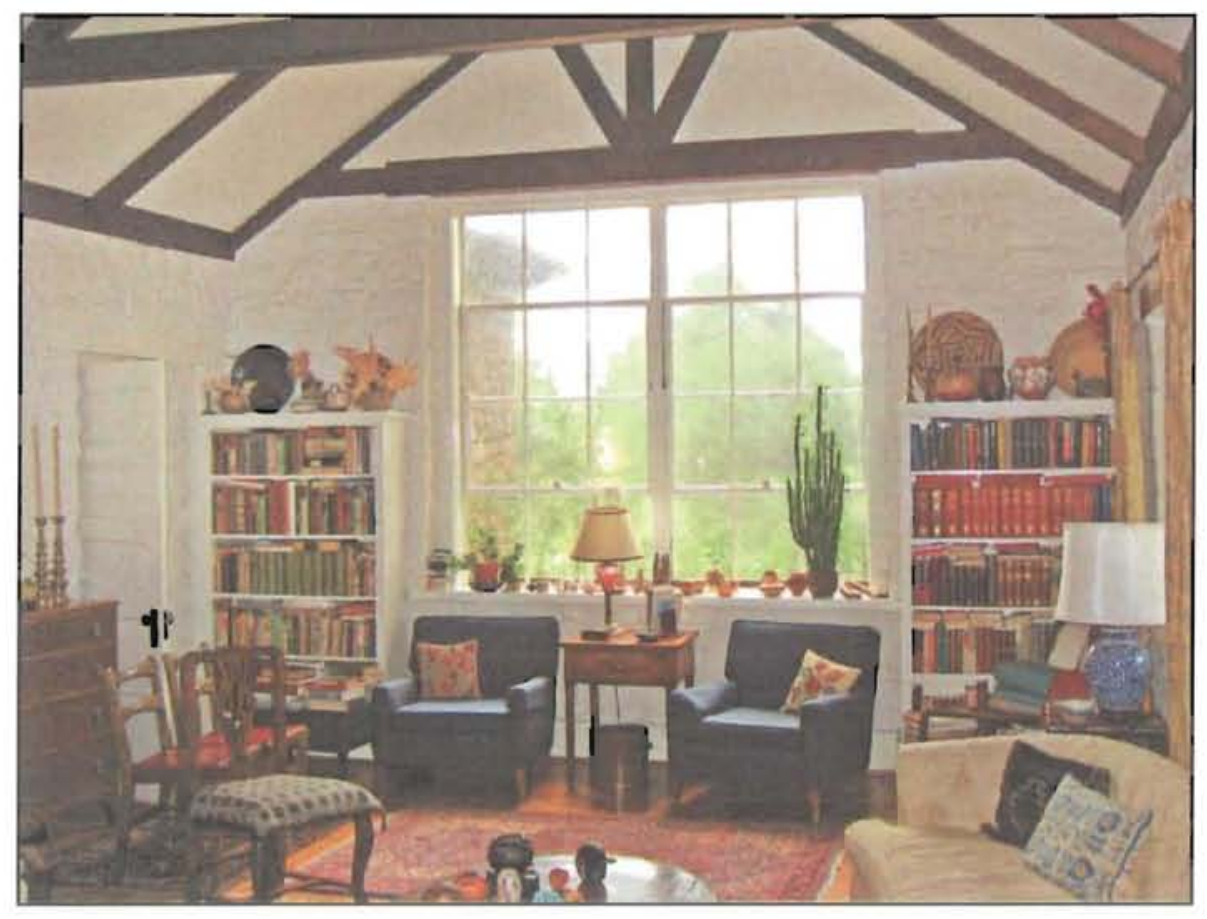
- LOS Alamos

The World's Greatest Science Protecting America
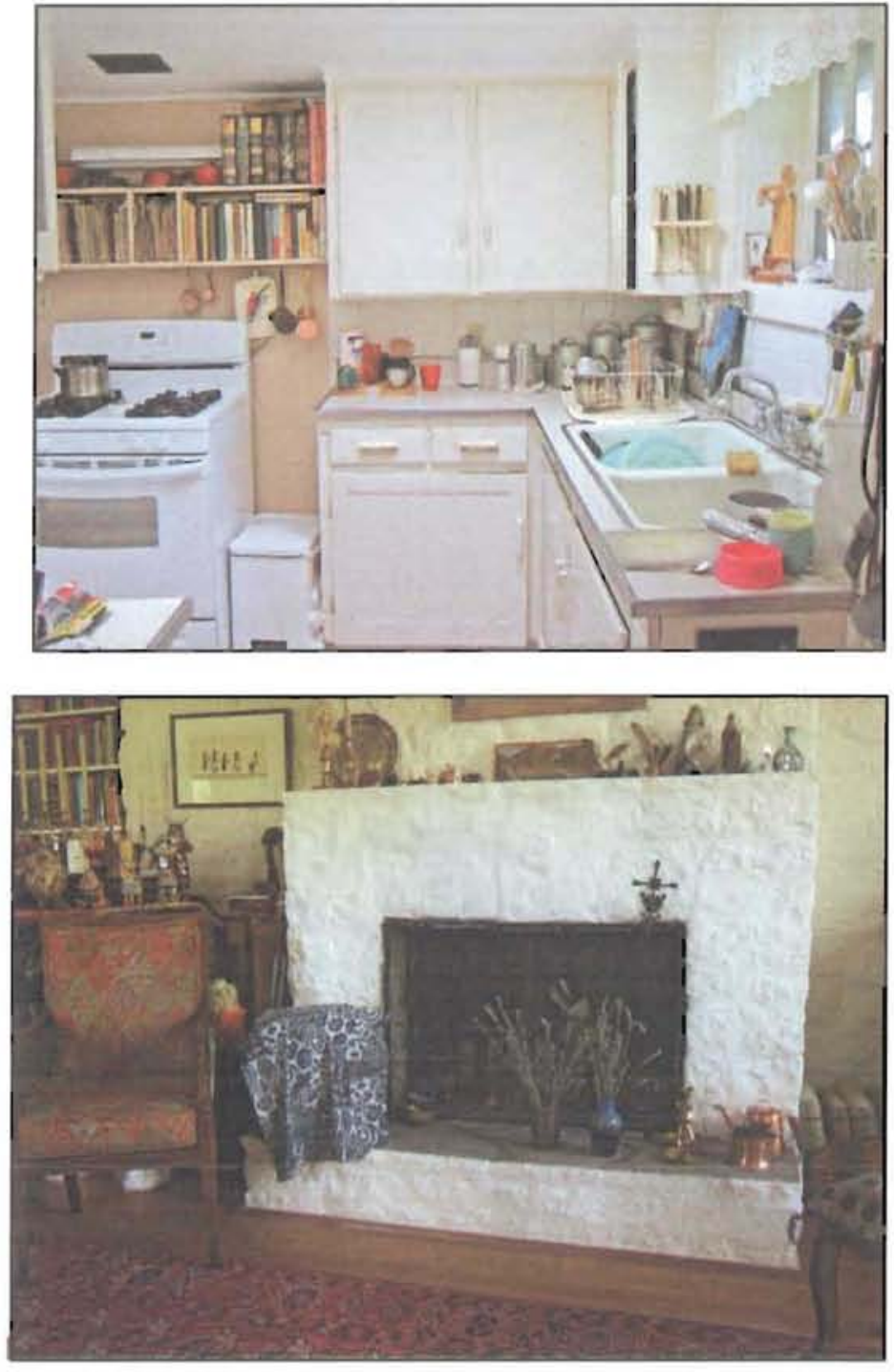


\section{Laboratory Technical Areas (TAs) TA-8: The "Little Boy" Gun Site (Gun Assembly Method)}

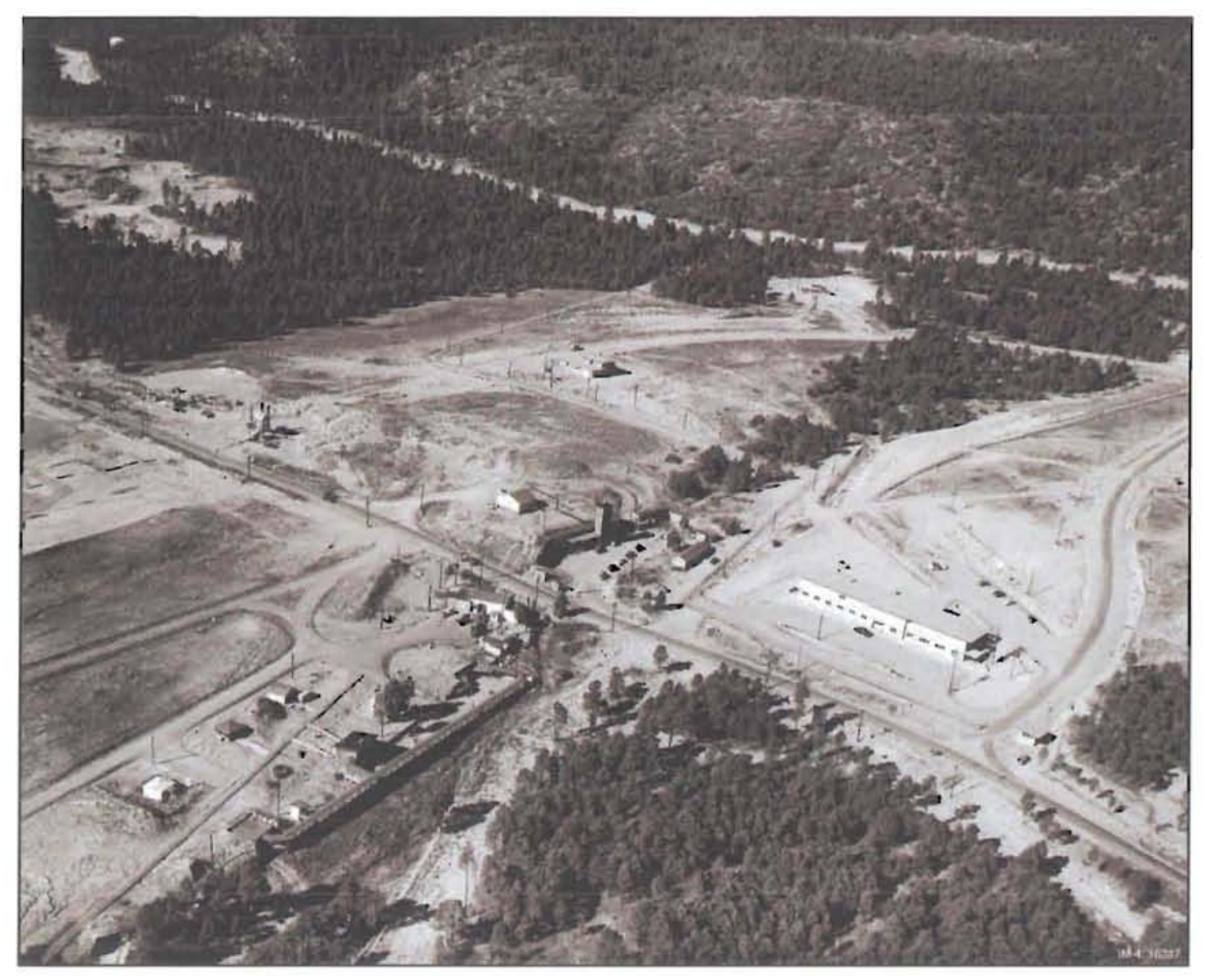




\section{TA-18: Plutonium Chemistry, Implosion Testing, and Criticality Research}

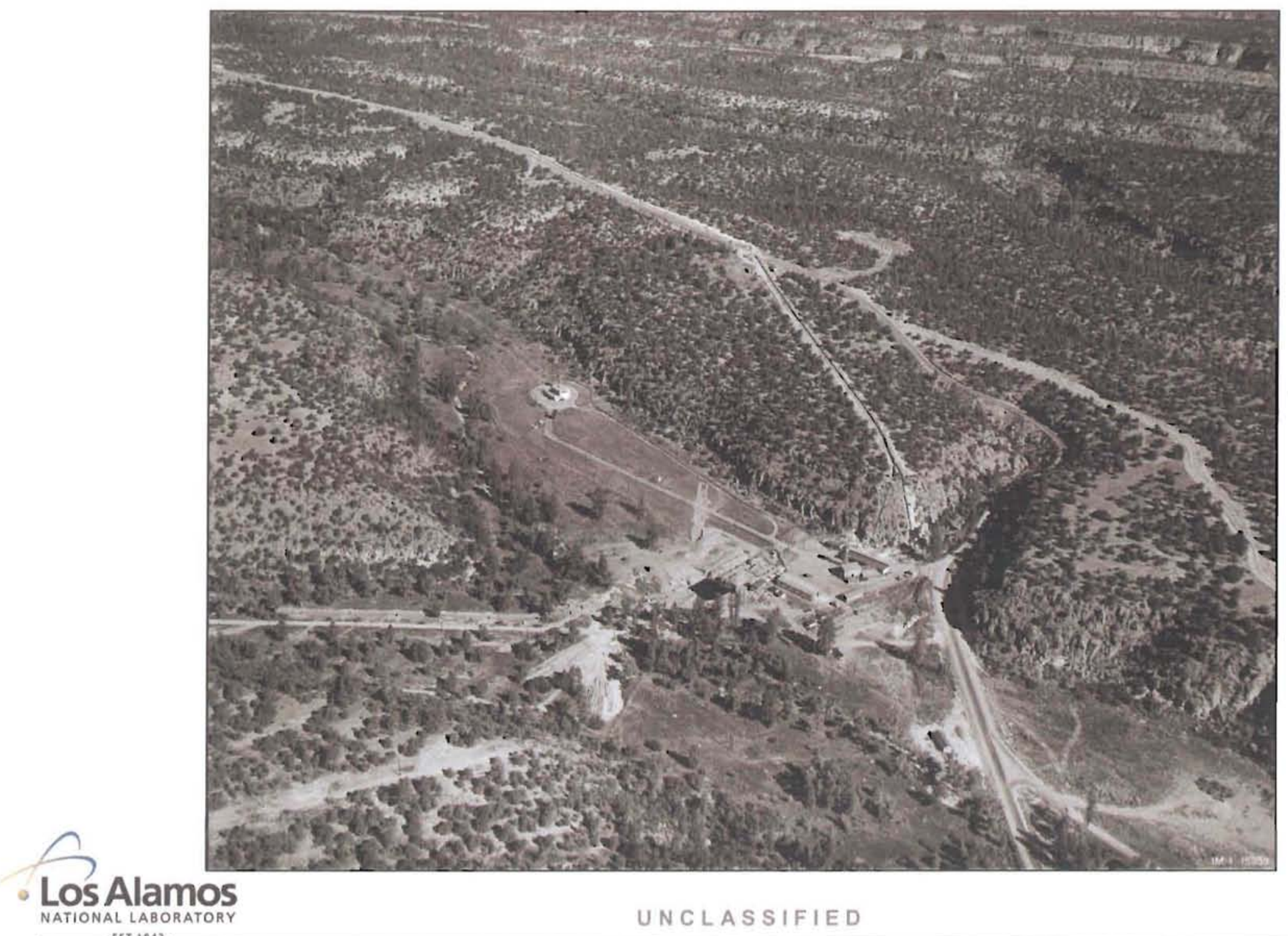




\section{TA-16: S-Site, "Fat Man" R\&D (Implosion Method)}

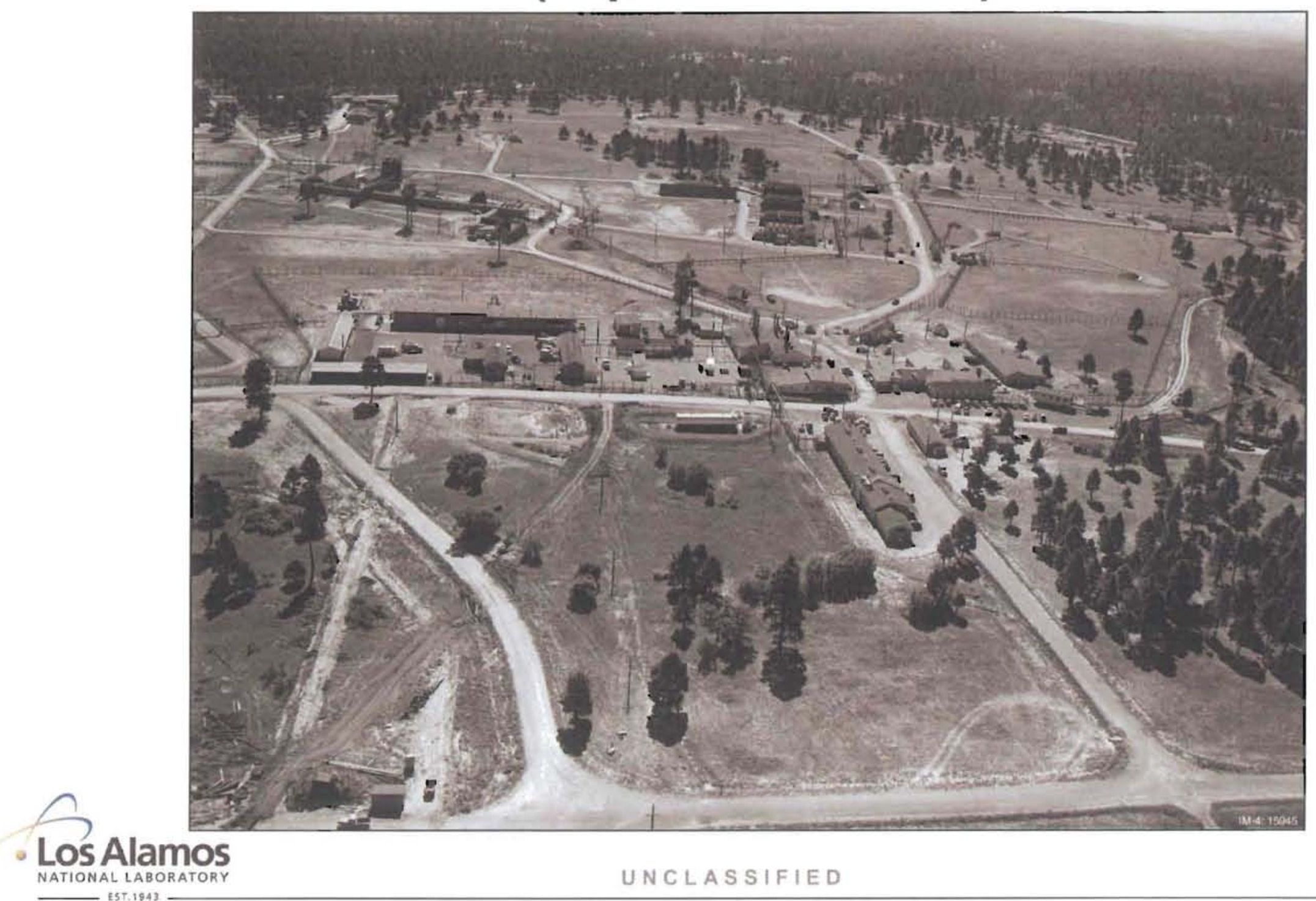

The World's Greatest Science Protecting America 


\section{TA-6: Plutonium Recovery}

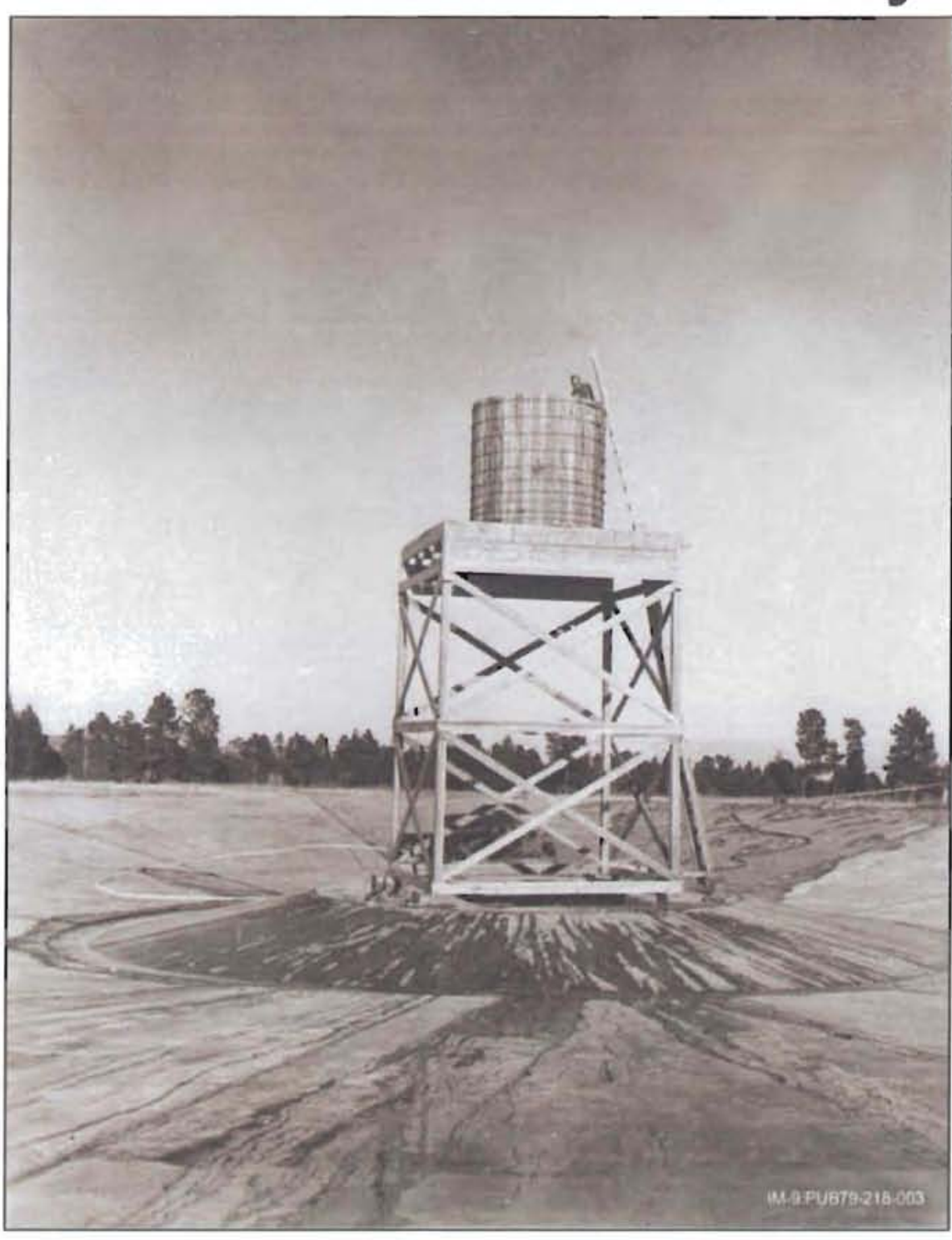




\section{TA-25: V-Site}

\section{(Trinity Device Assembly)}

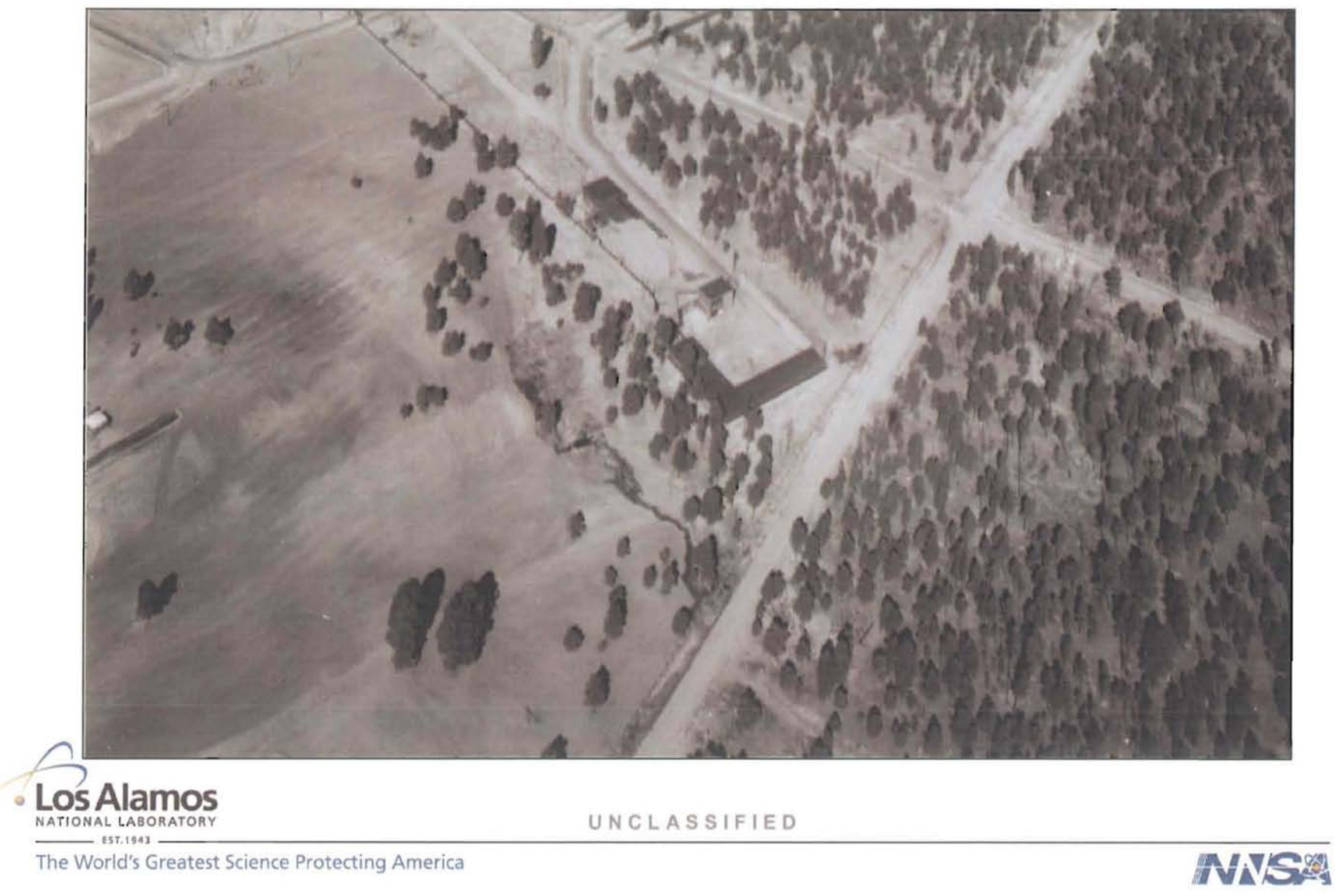




\section{TA-22: "Fat Man" Design and Assembly}

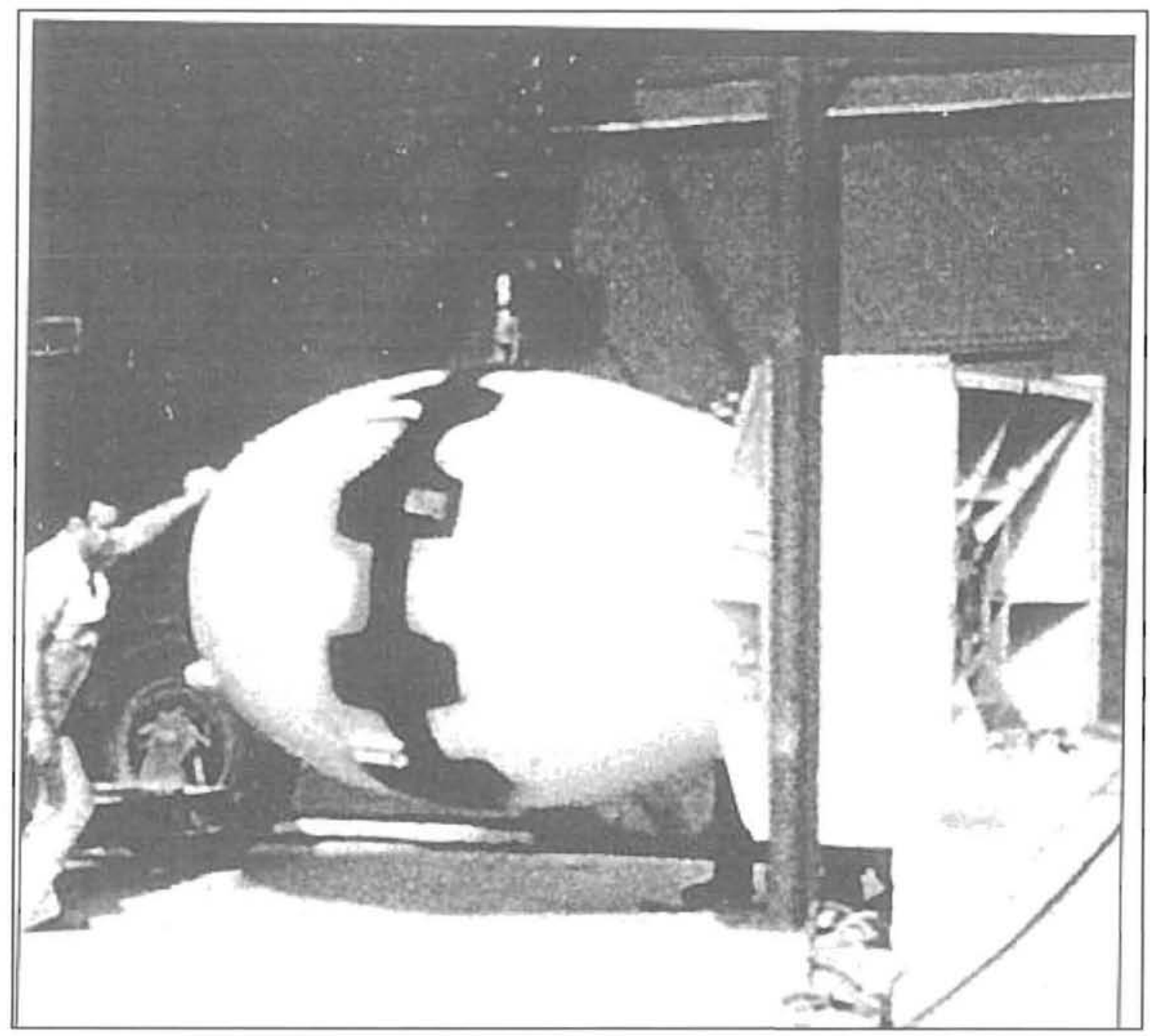




\section{Los Alamos National Laboratory Manhattan Project Historic Preservation Activities}

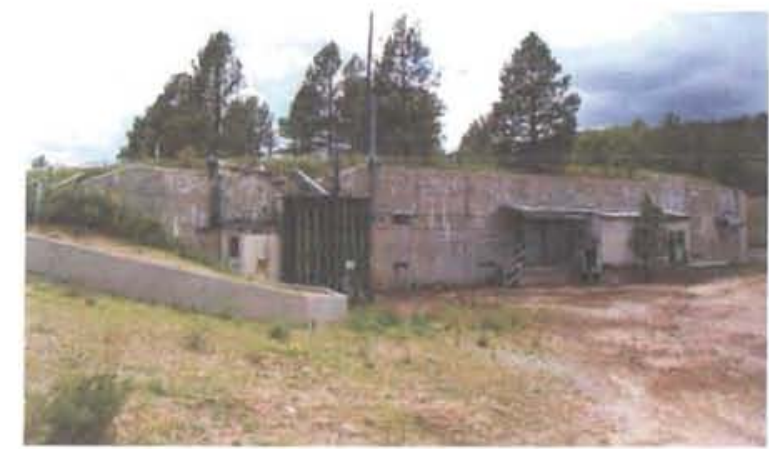

Gun Site

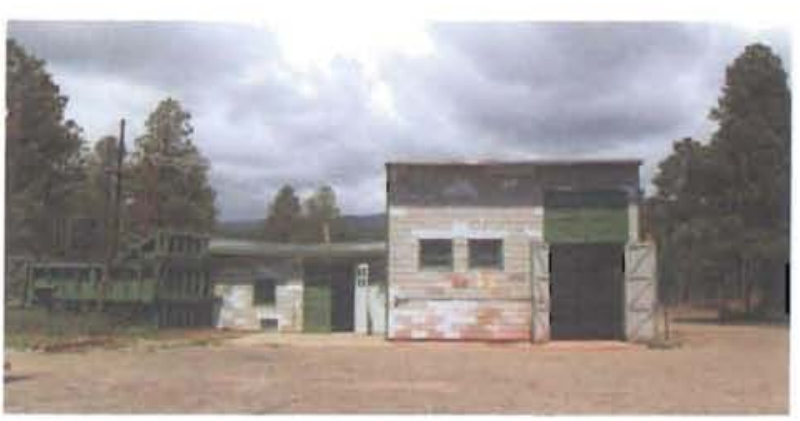

V-Site

- Los Alamos

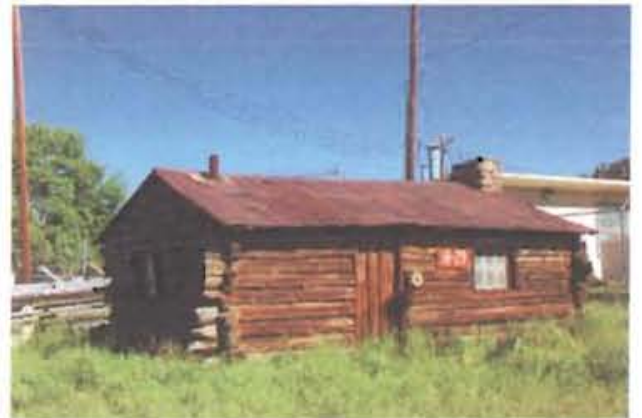

Pond Cabin

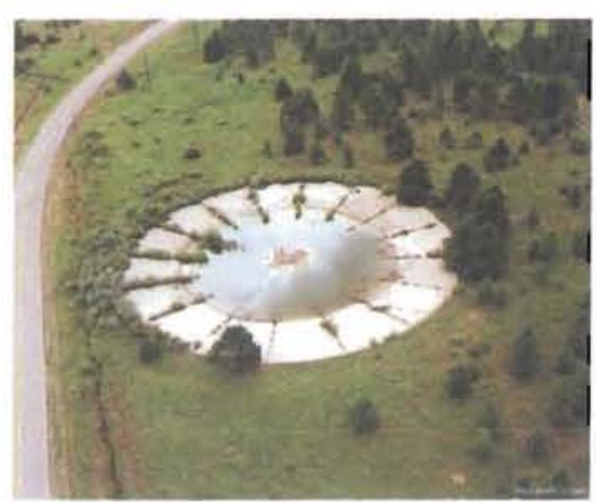

Concrete Bowl

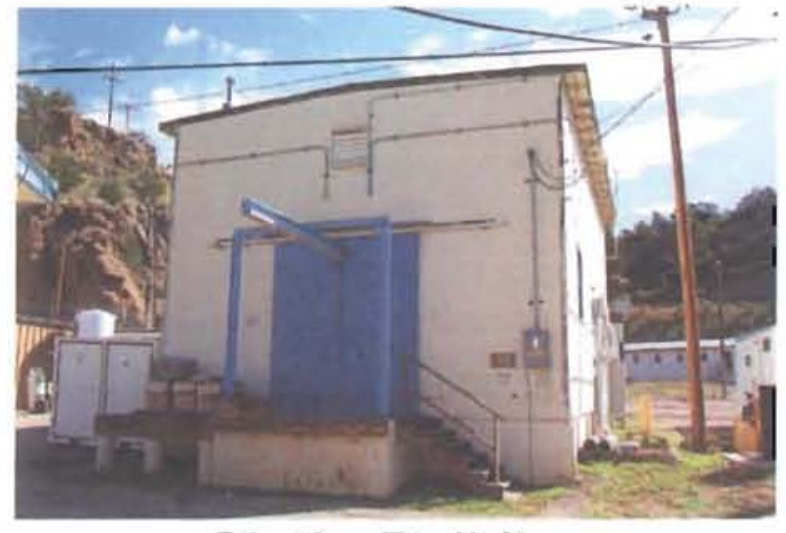

Slotin Building

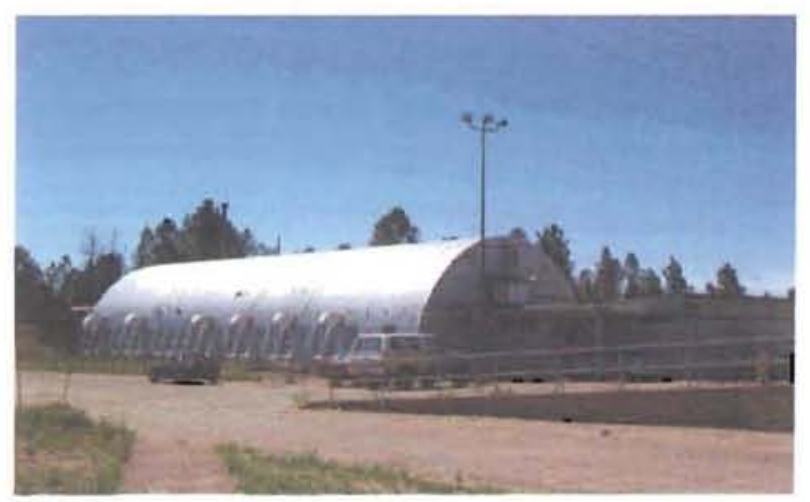

Quonset Hut 


\section{TA-8: The Gun Site}

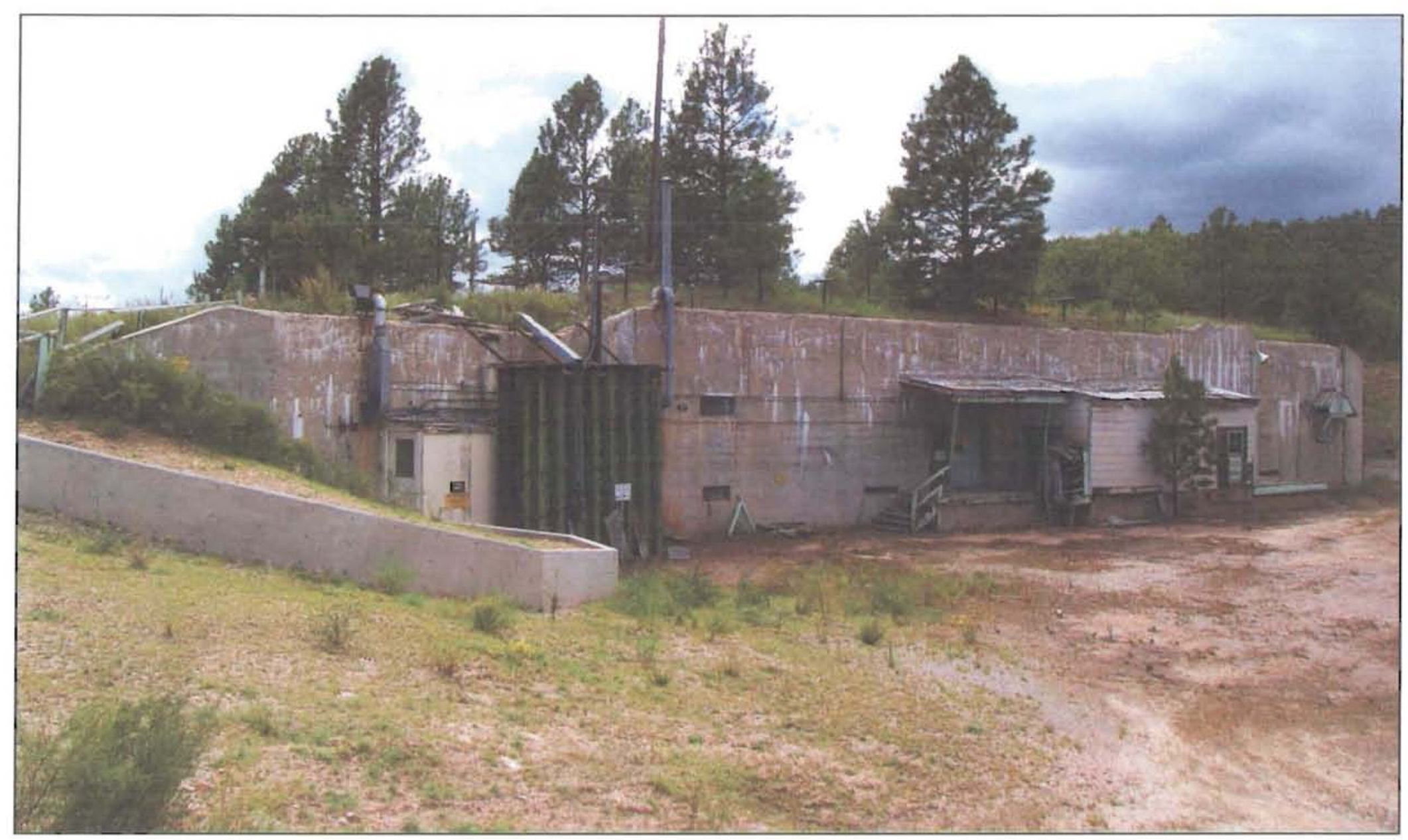

\section{- Los Alamos}

UNCLASSIFIED 


\section{Gun Site Phased Restoration Project}

FY 08 Priorities

- Restoration plan

- Clean up phase

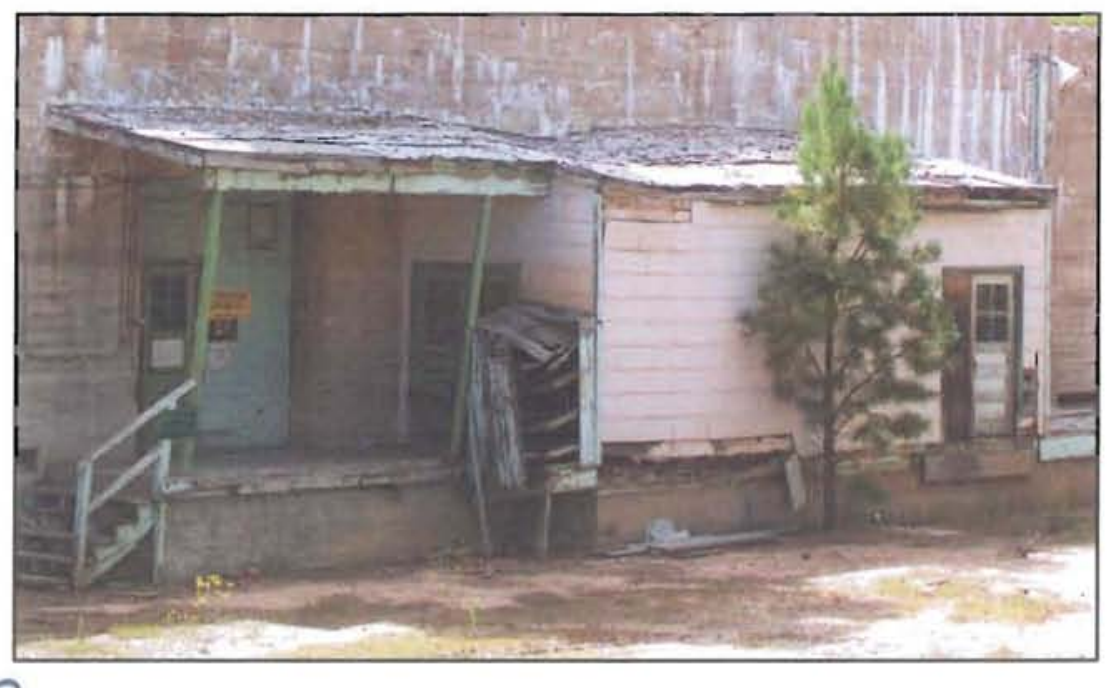

UNCLASSIFIED

- Los Alamos

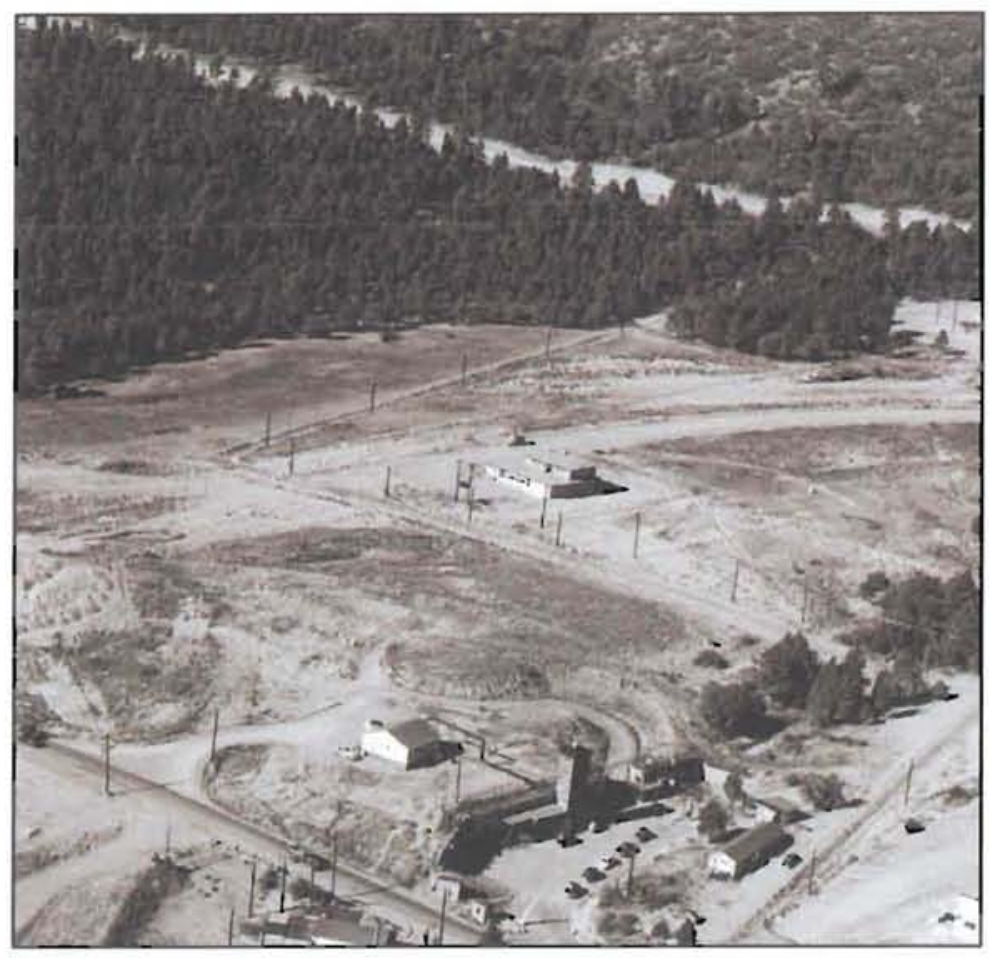




\section{TA-18: Pajarito Site}
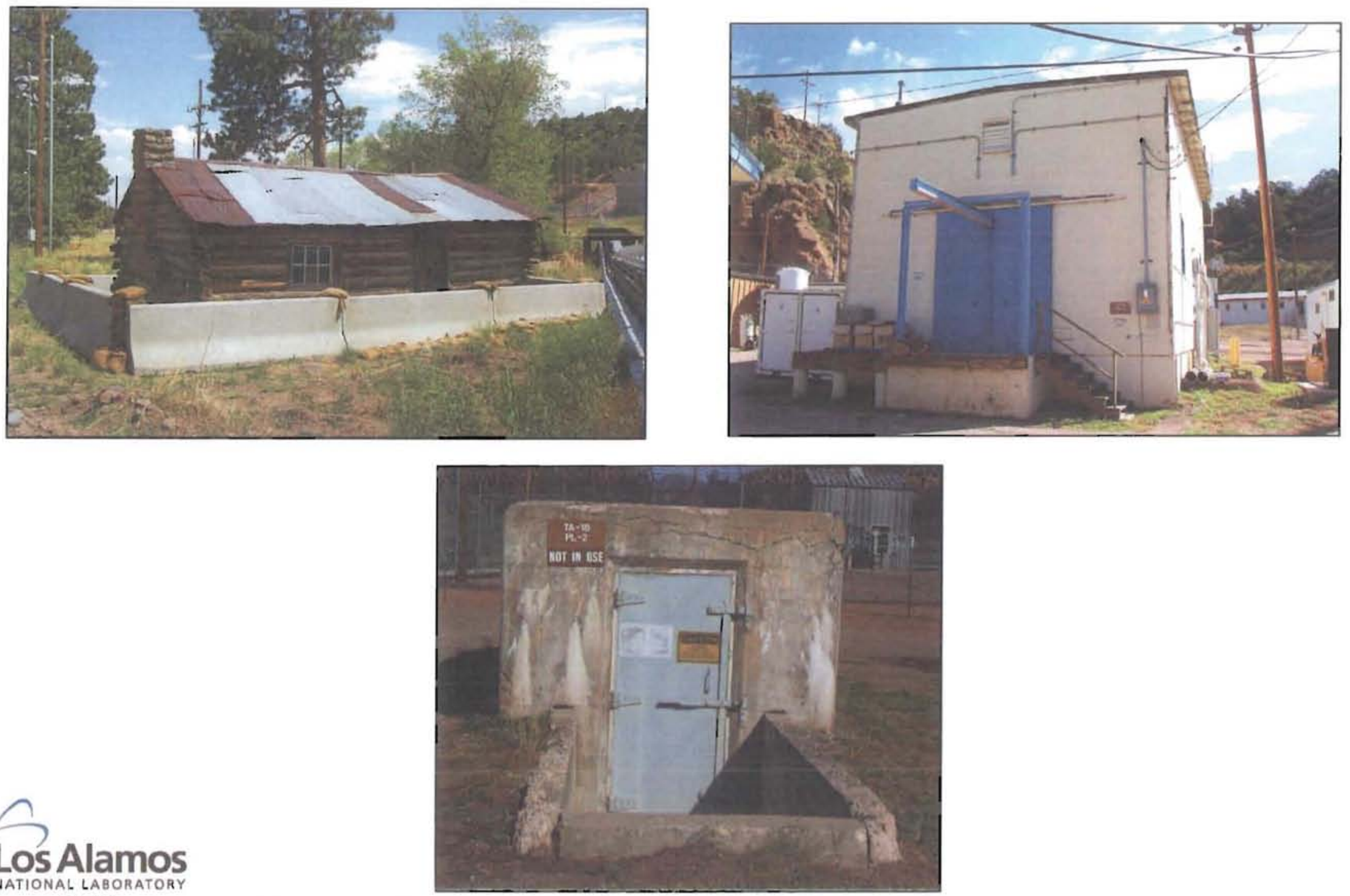

Los Alamos NATIONAL LABORATORY

The World's Greatest Science Protecting America

NAS 


\section{TA-6: The Concrete Bowl (Water Recovery Method)}

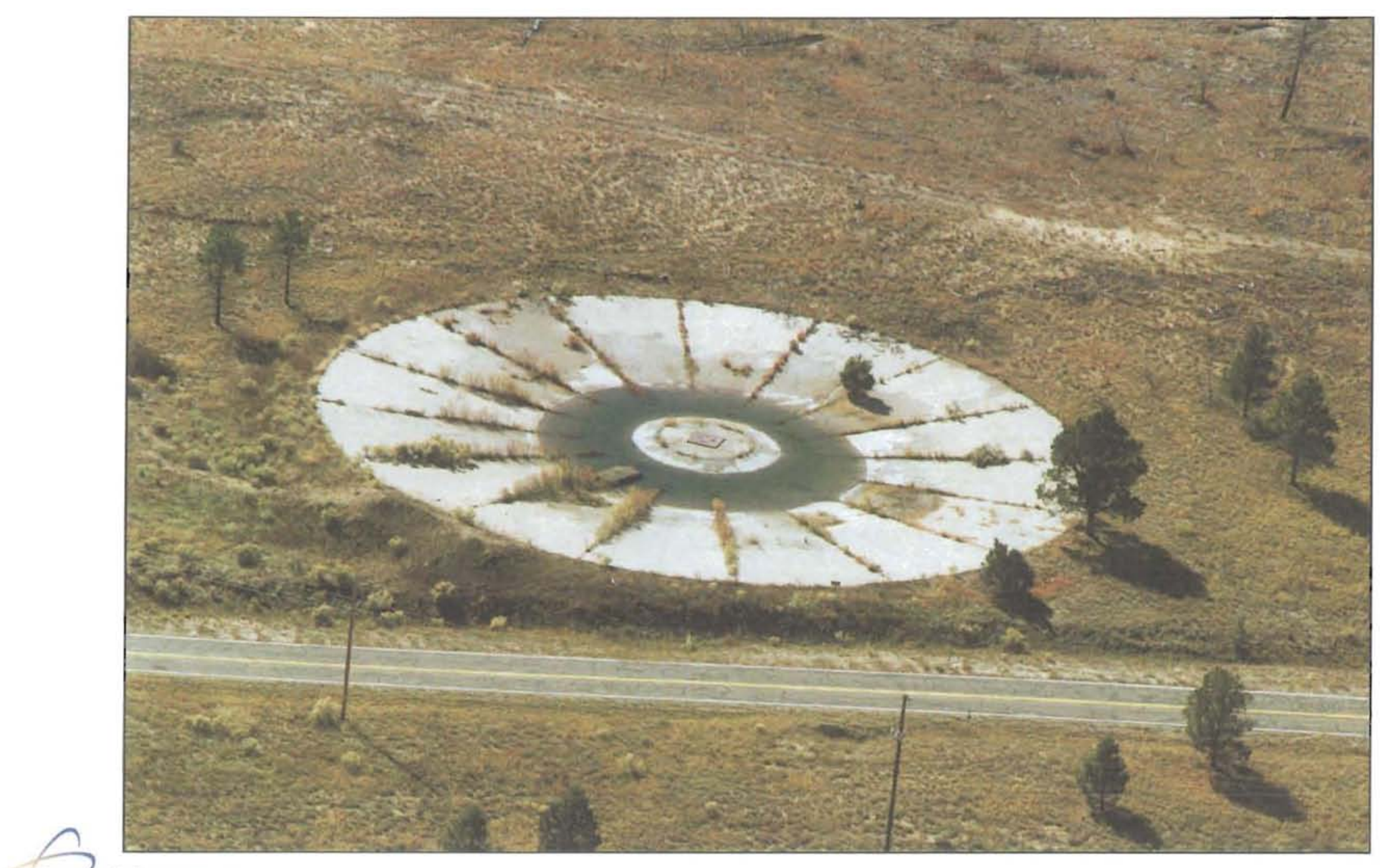




\section{TA-22: The "Fat Man" Quonset Hut}

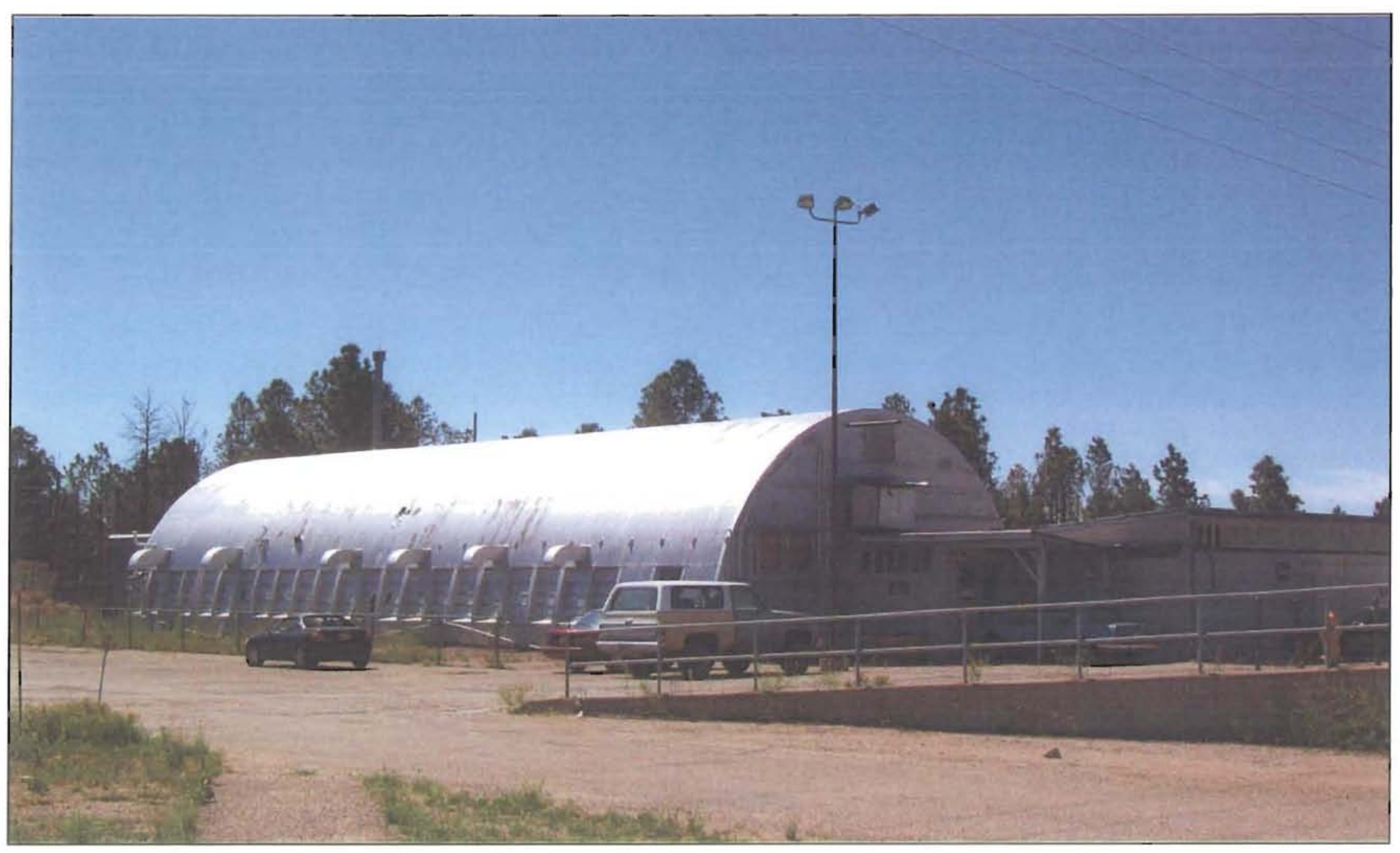

- LosAlamos 


\section{V-Site Restoration Project}
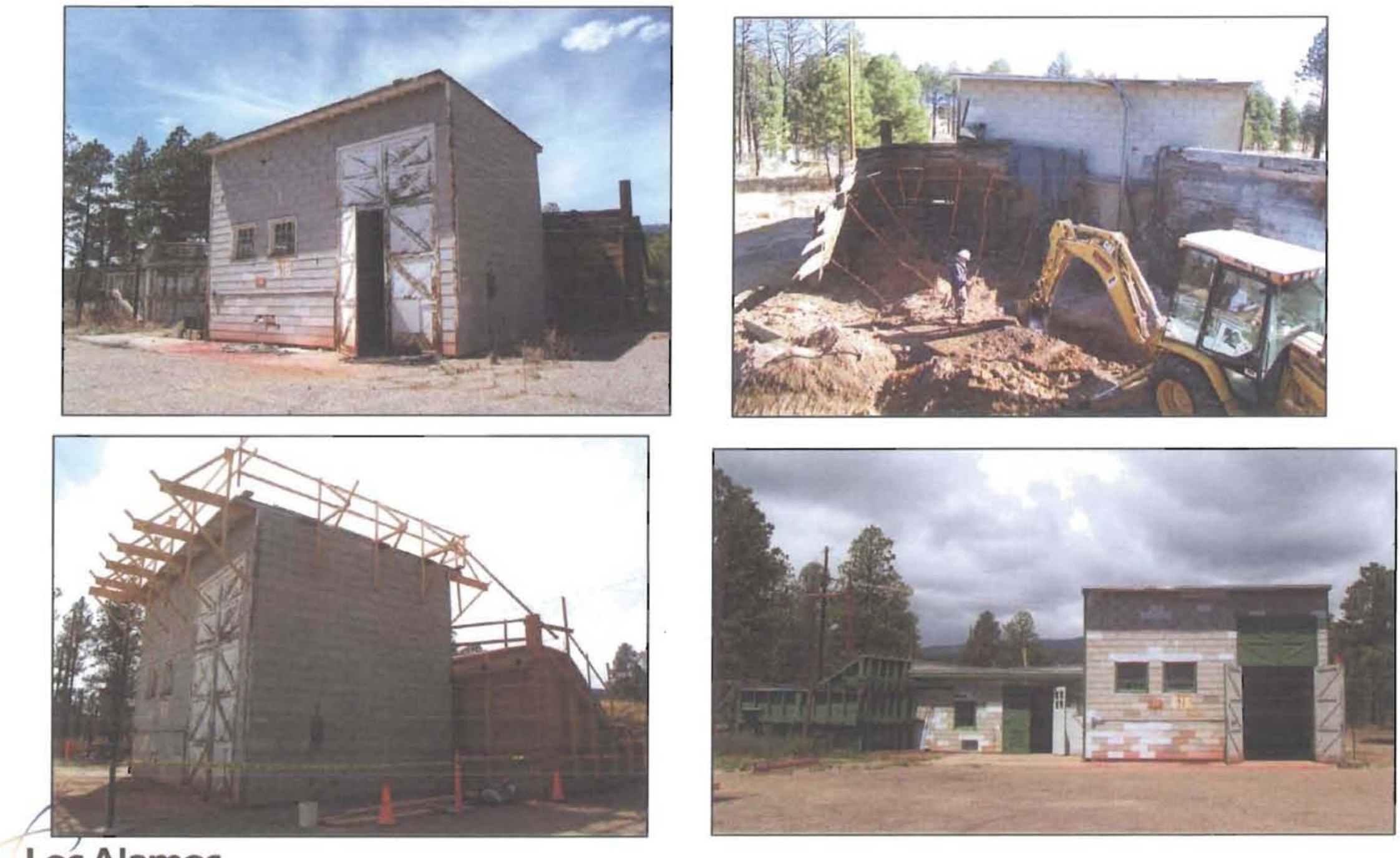

- Los Alamos 


\section{Three Restoration Phases:}

1) Berm and Back Walls (also asbestos abatement and dirt removal)

2) Roof Repairs

3) Cosmetic (doors, windows, and shingles)
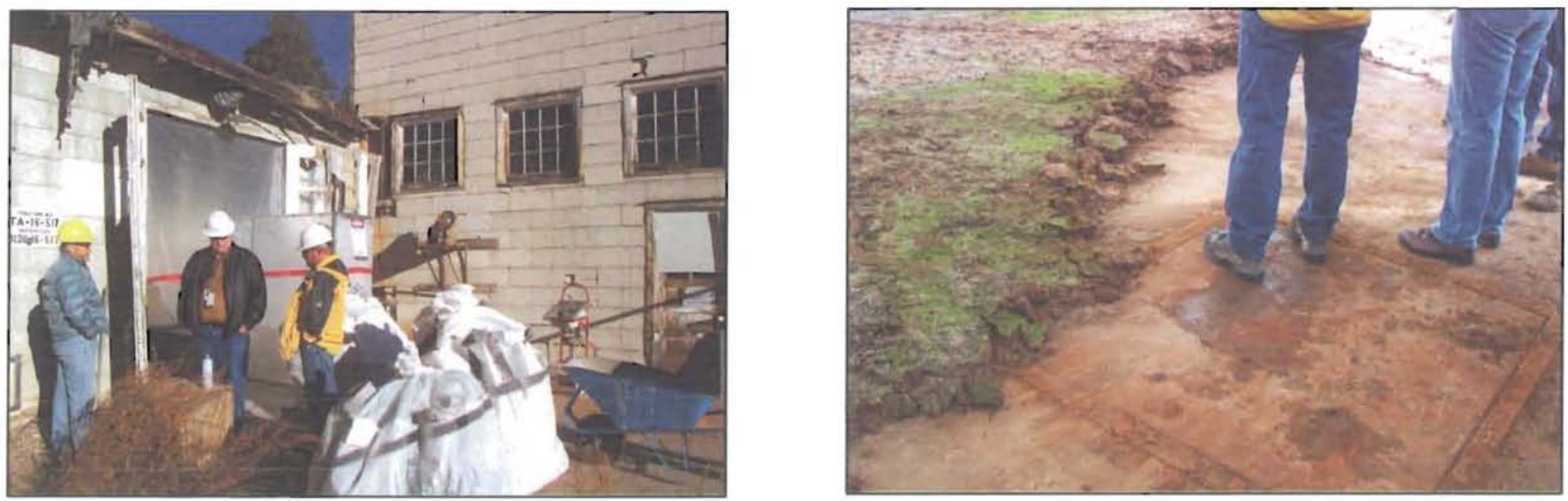

- Los Alamos 


\section{Condition of Roof (Building 16-517)}

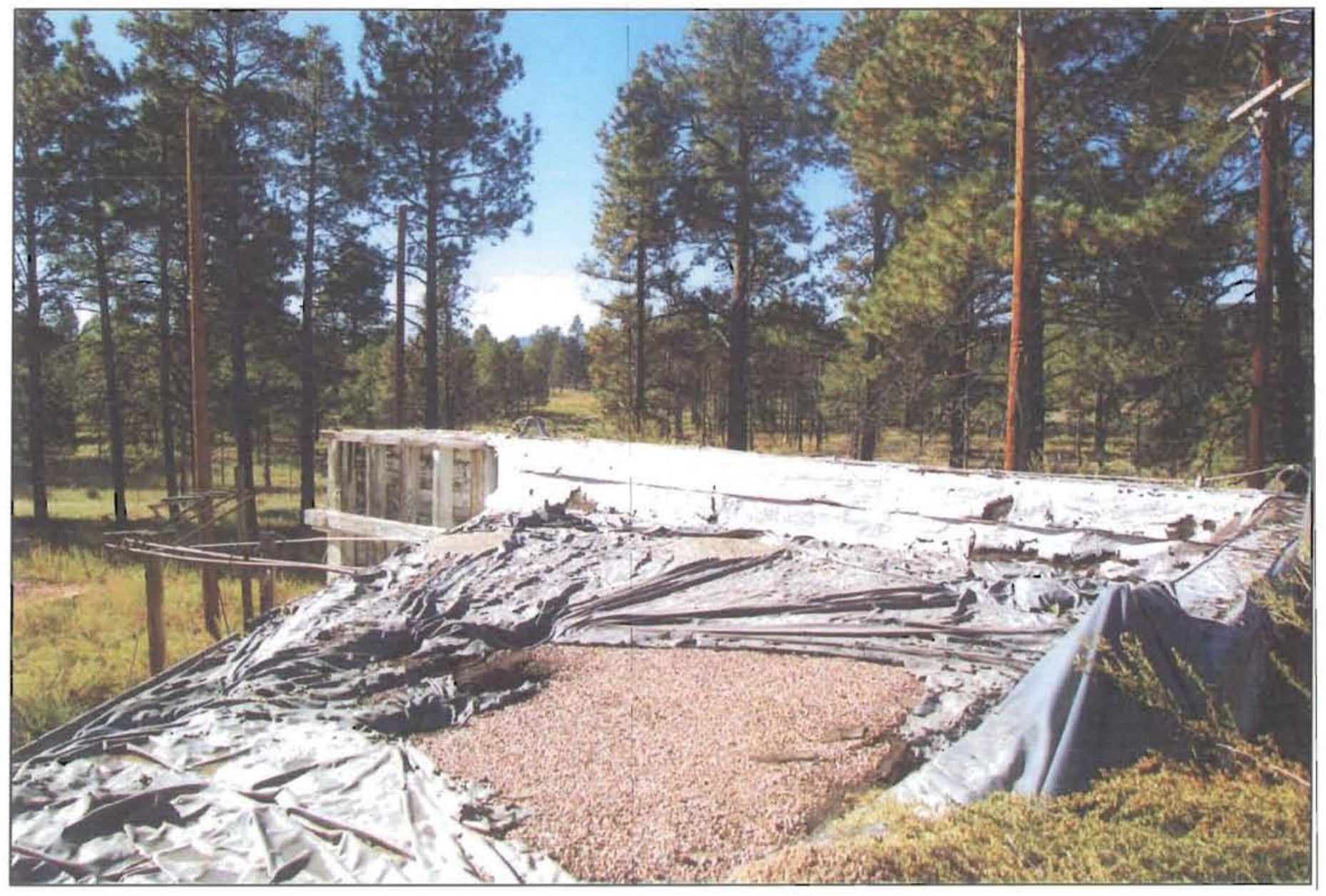

- Los Alamos 


\section{Pre-Restoration Condition of Berm and Berm Retaining Walls}

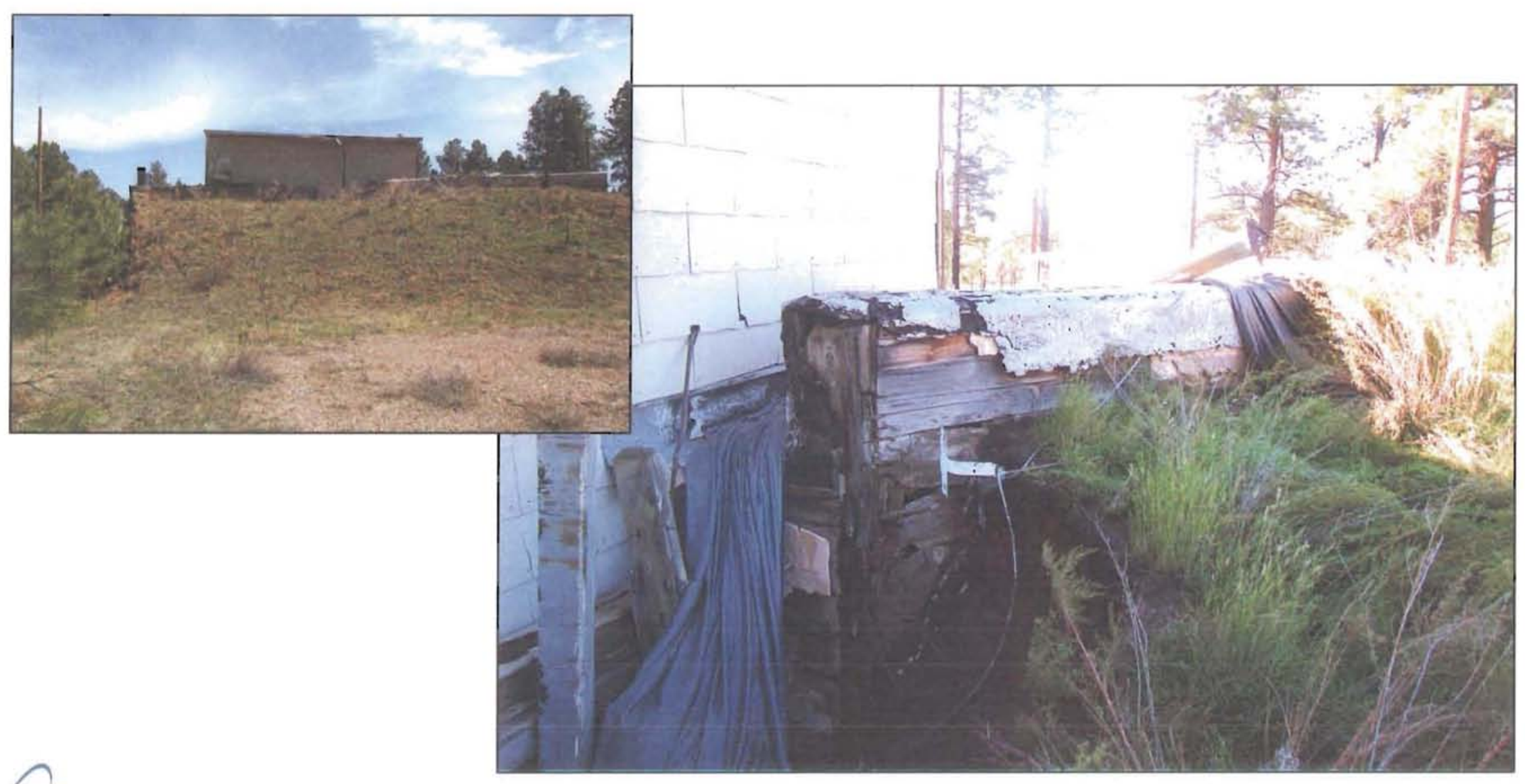

- Los Alamos 


\section{Exterior Condition: Broken Shingles, Deteriorated Wood}

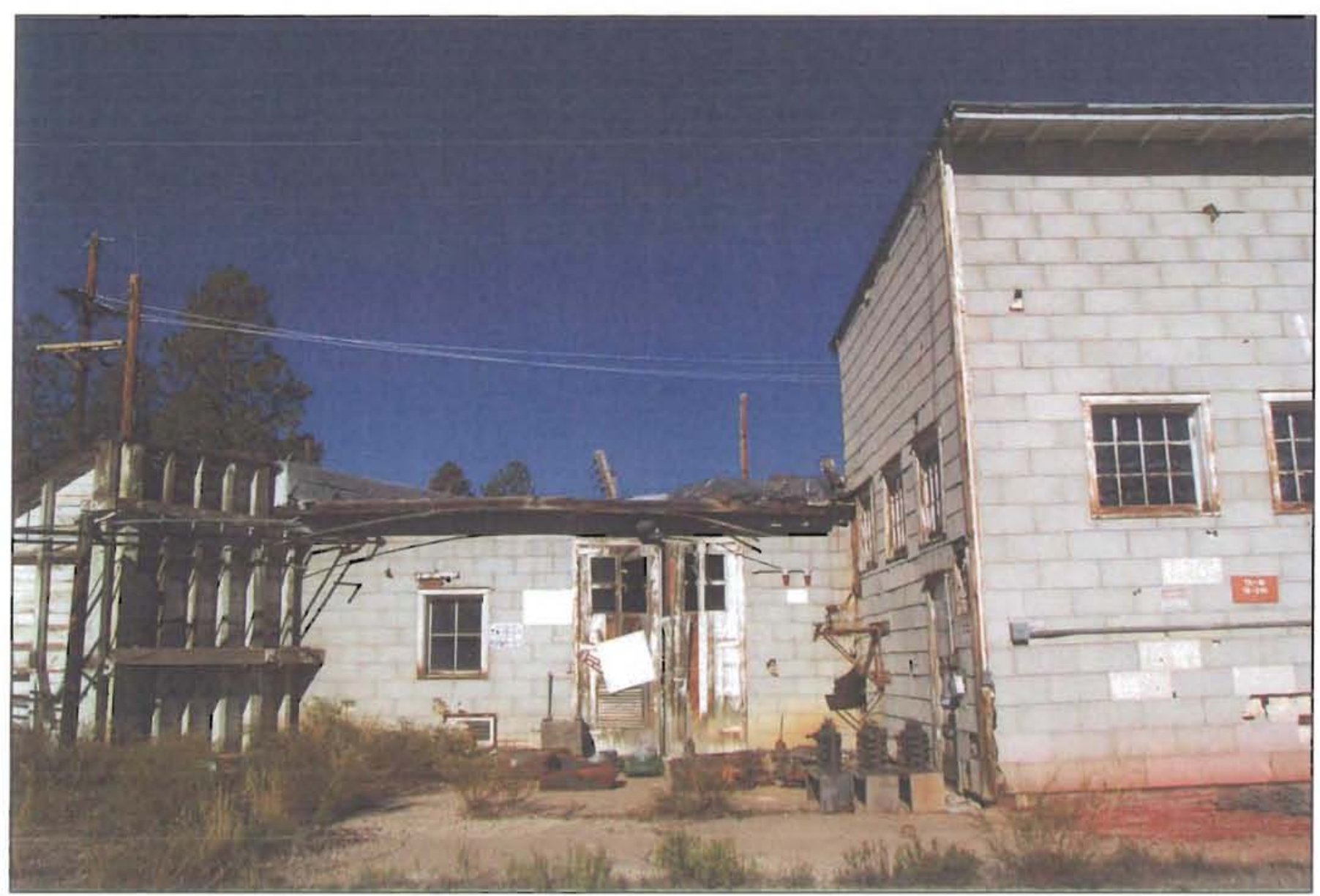




\section{Key Activities (2005-2006) Berm Removal}

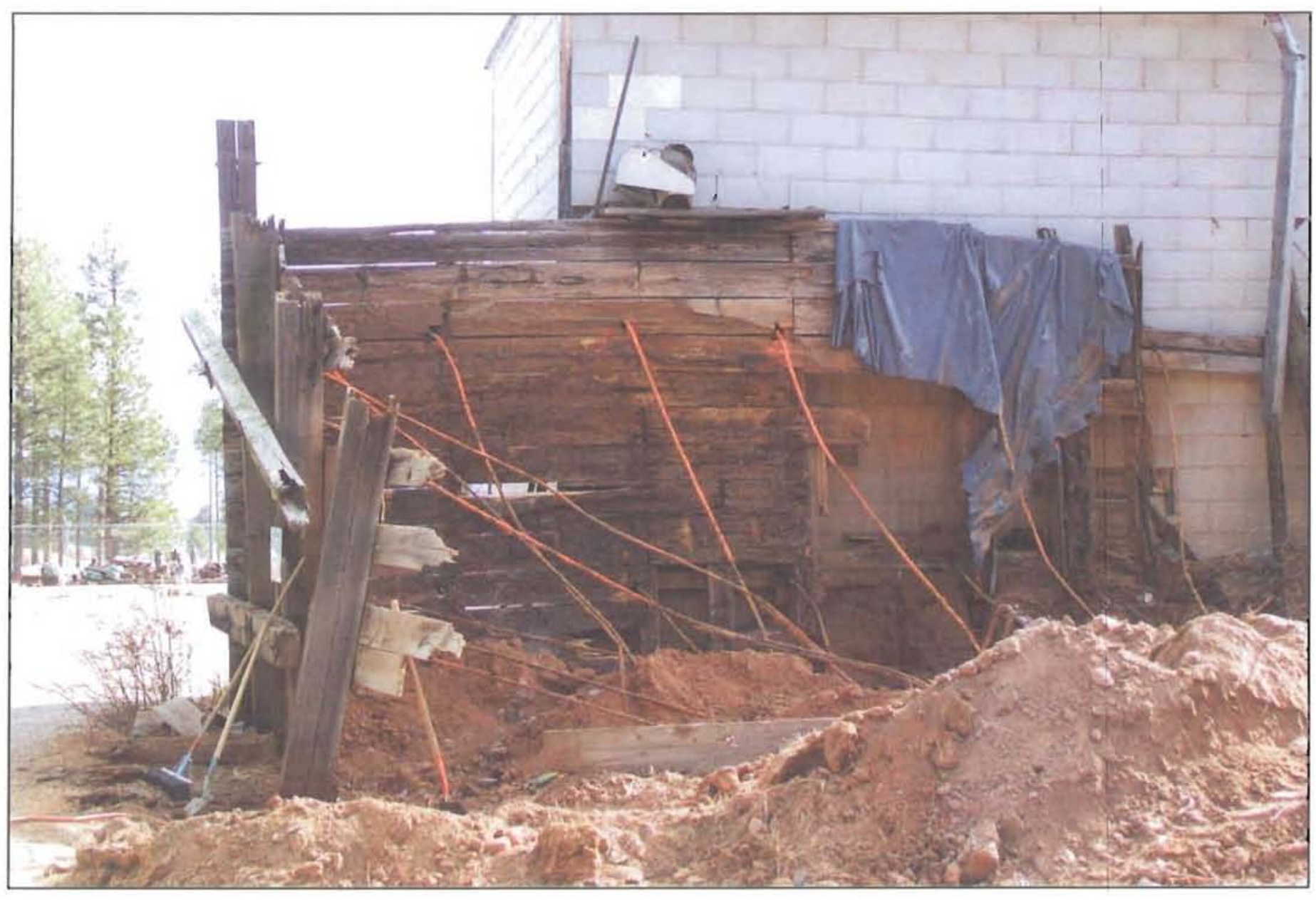

- Los Alamos 


\section{Berm Wall Removal (Building 16-516)}

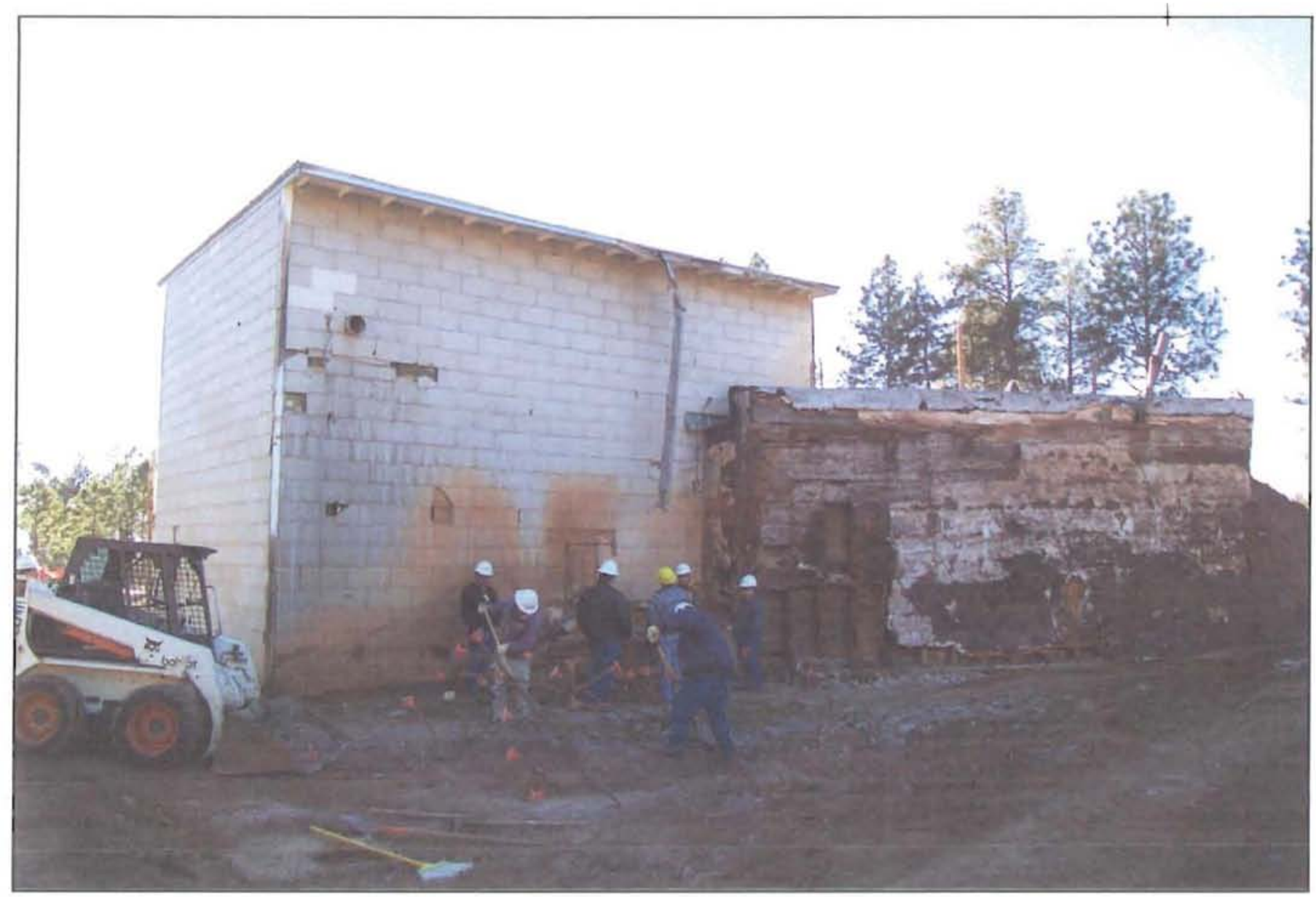

- Los Alamos 


\section{Back Wall Repairs}

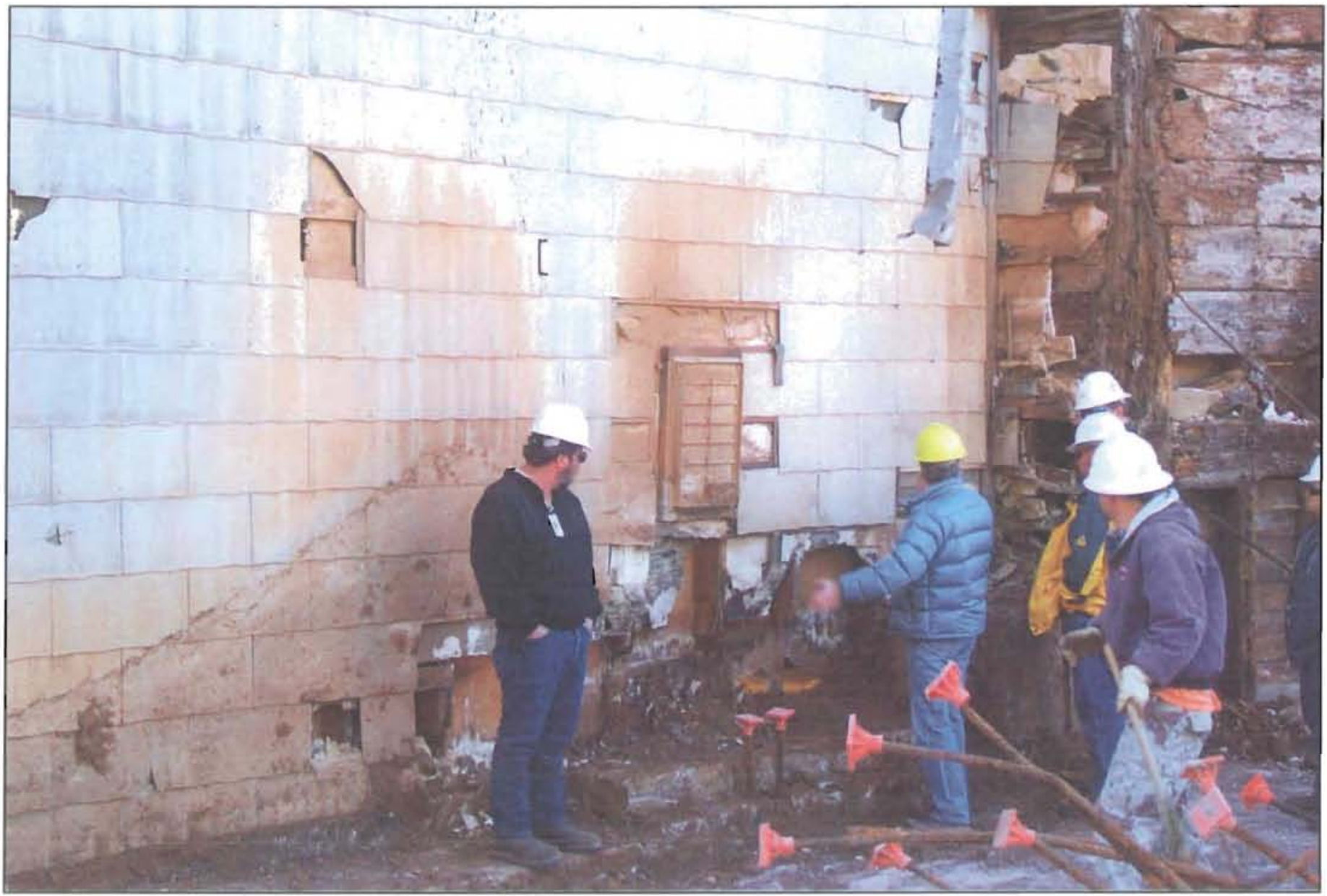

- LOSAlamos

UNCLASSIFIED

The World's Greatest Science Protecting America

NAS 


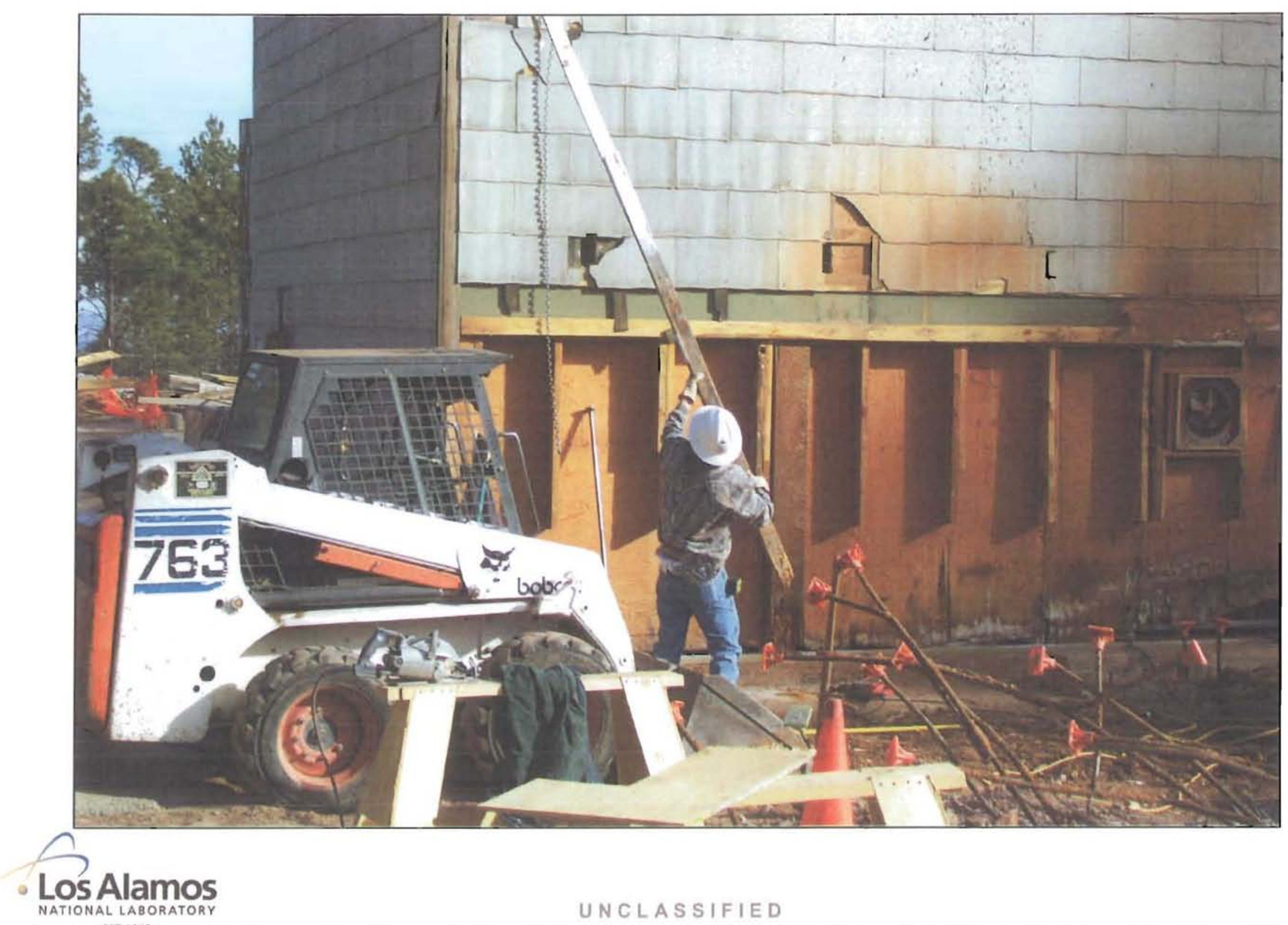




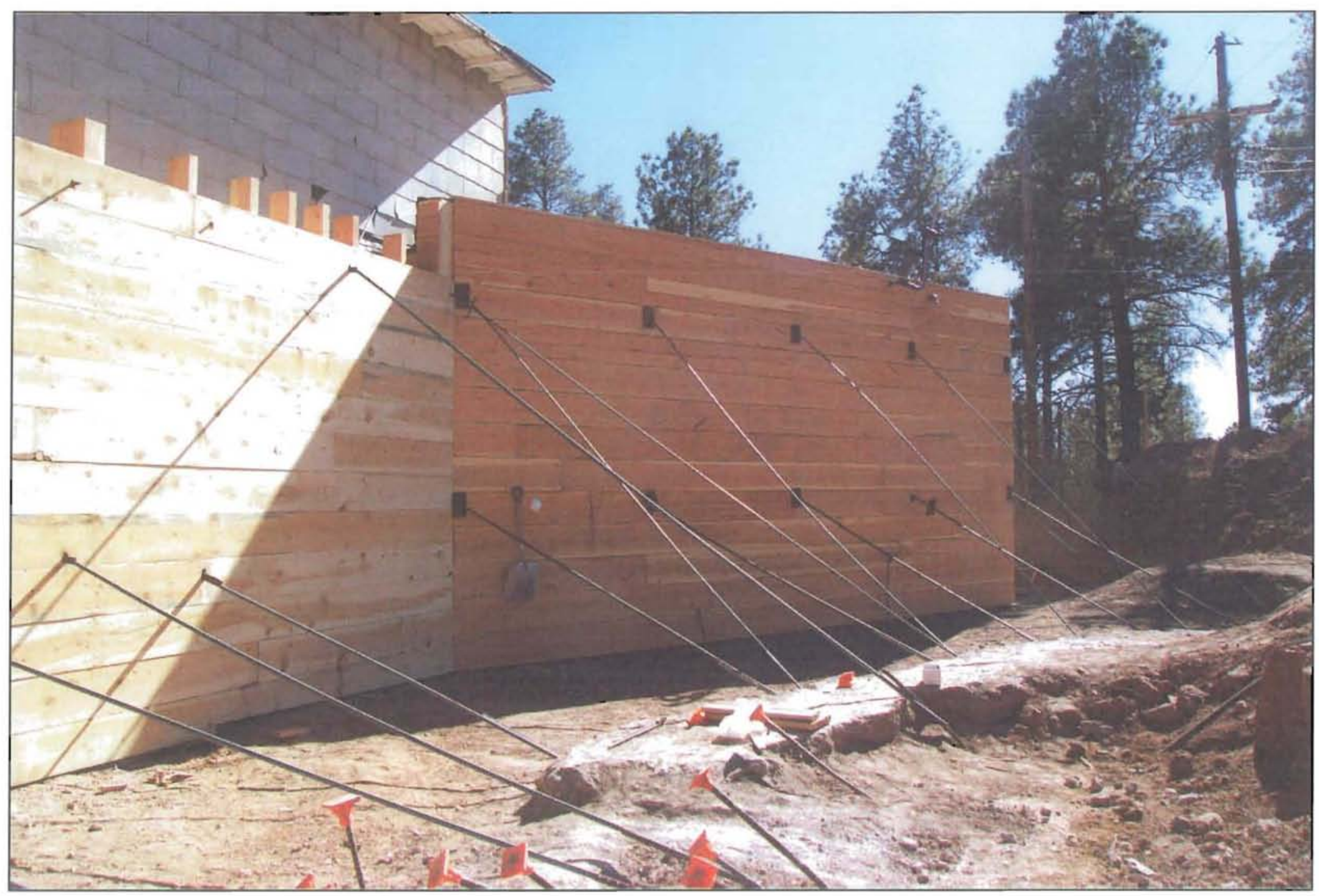




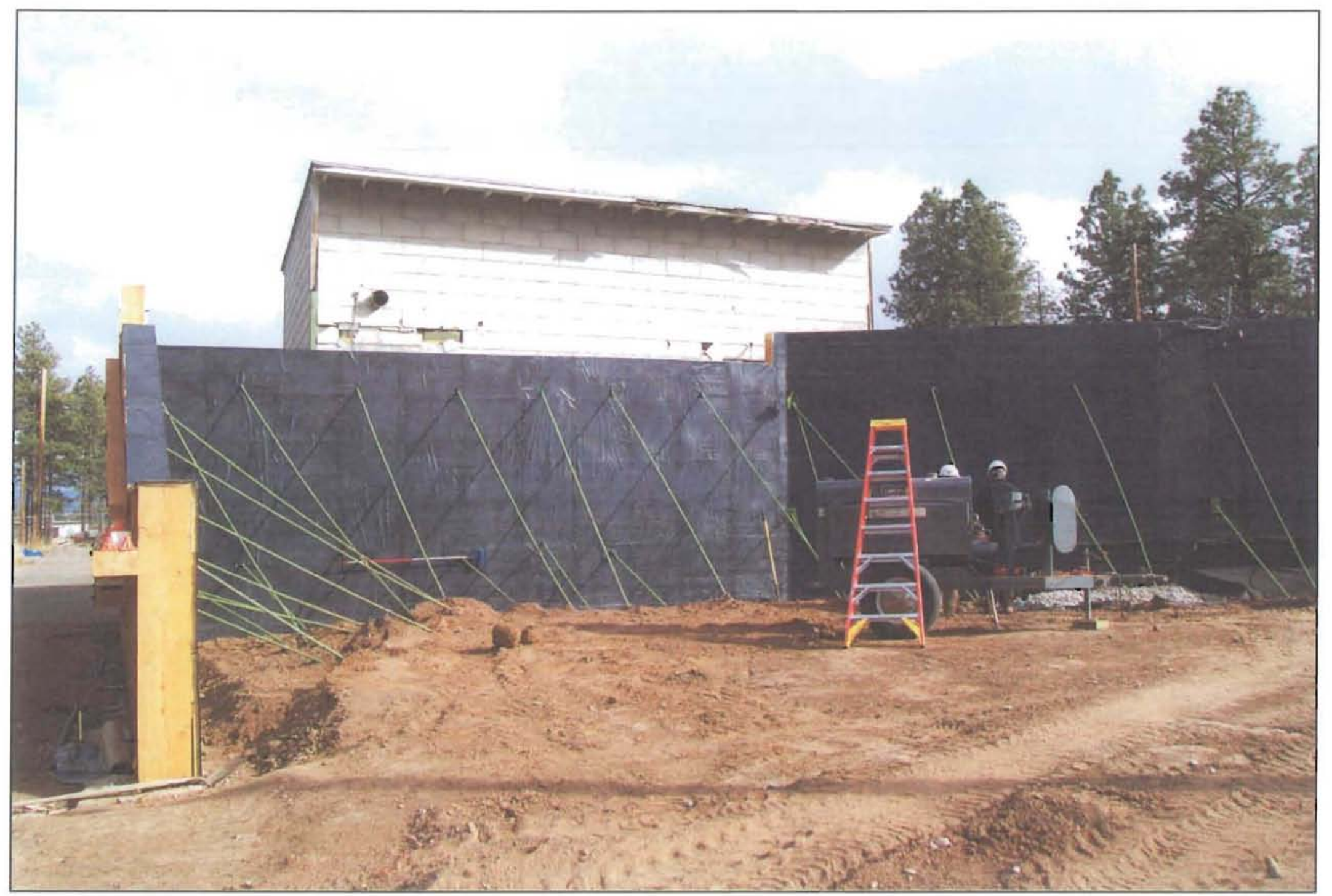

- Los Alamos NATIONAL LABORATORY

UNCLASSIFIED

The World's Greatest Science Protecting America

NASe: 


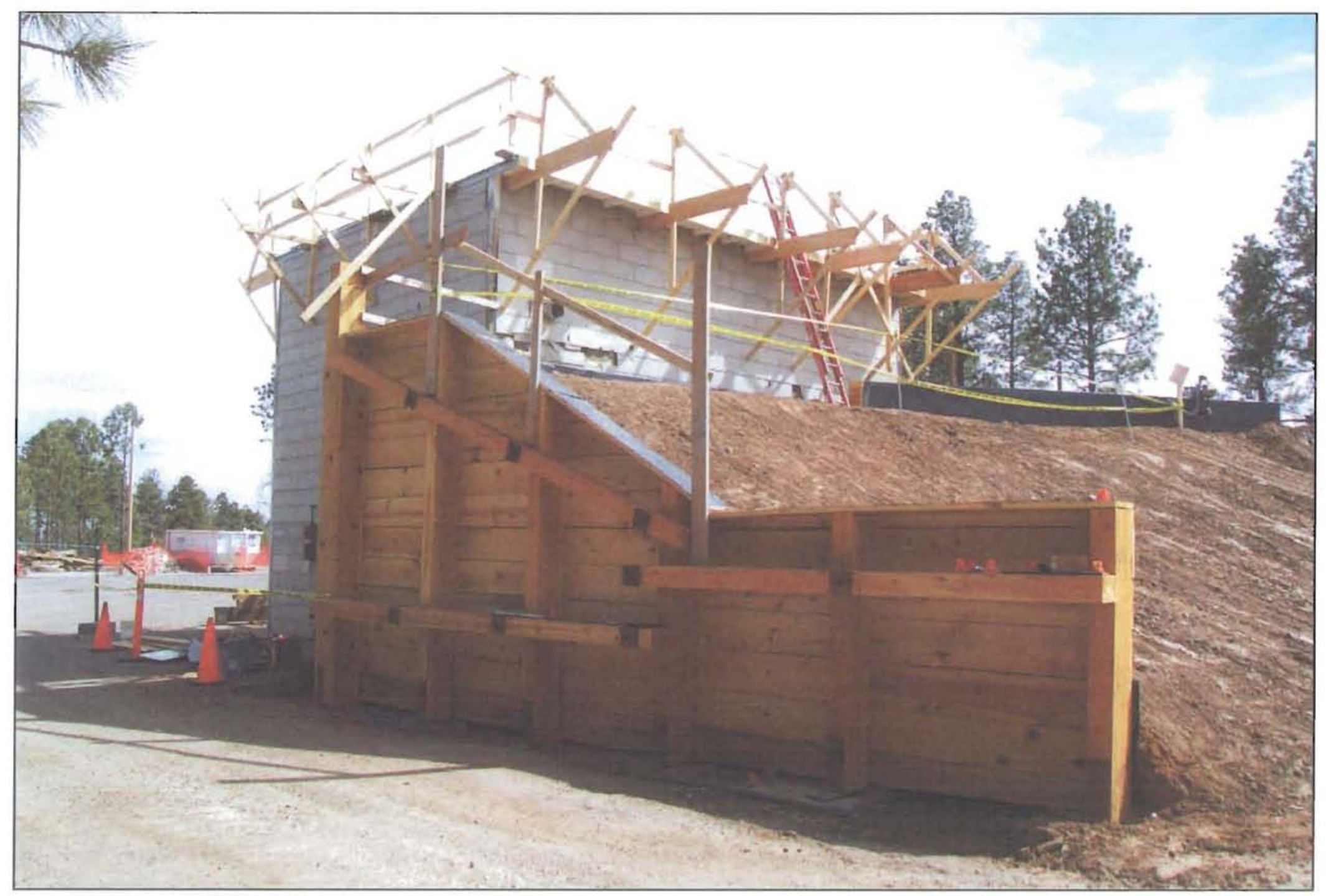

- Los Alamos

UNCLASSIFIED

The World's Greatest Science Protecting America 


\section{Berm Rebuilding - French Drain}

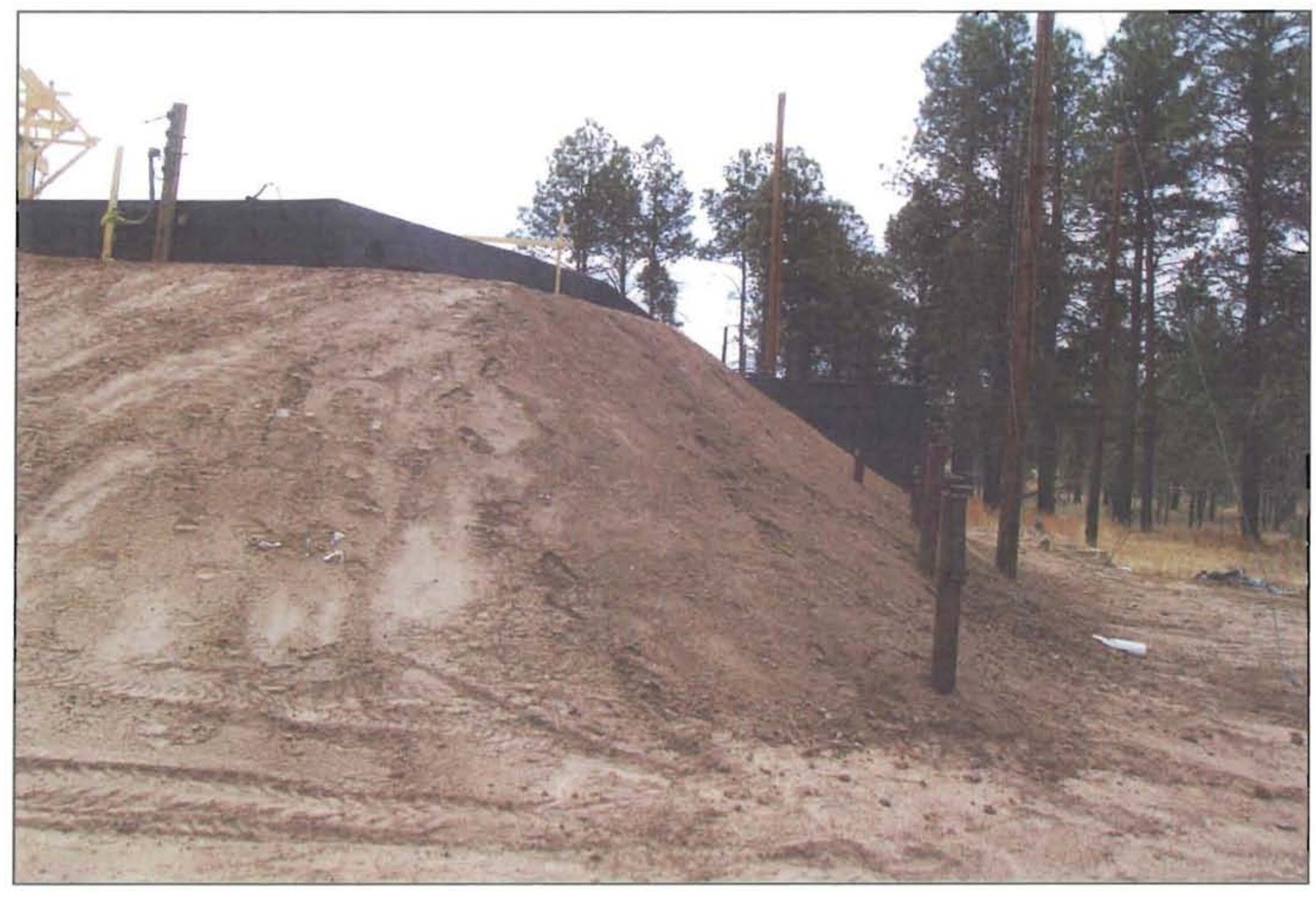

- Los Alamos NATIONAL LABORATORY

UNCLASSIFIED 


\section{Re-roofing, Re-configure Roof Drainage}

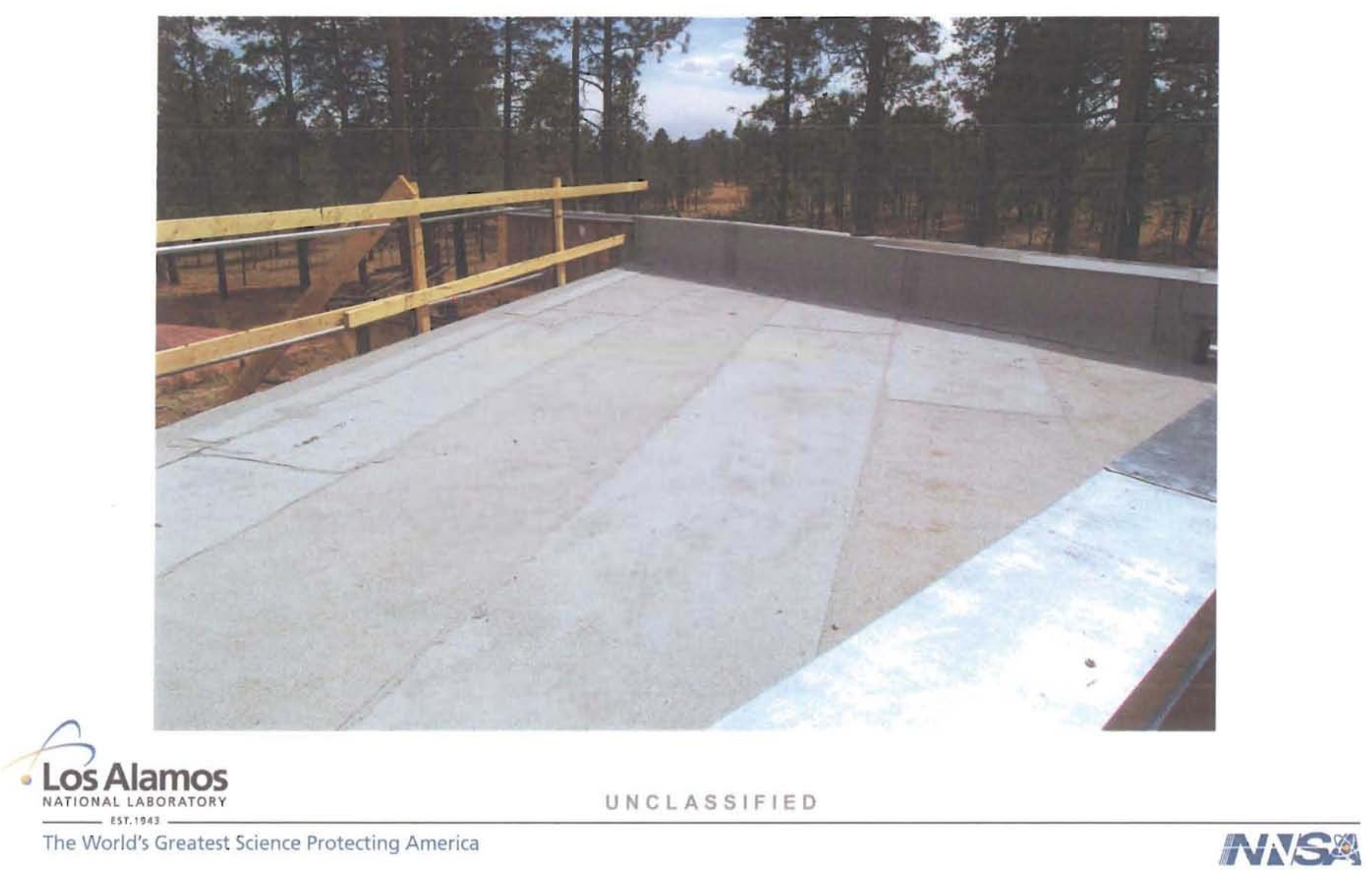




\section{Exterior Repairs and Cosmetic Restoration}

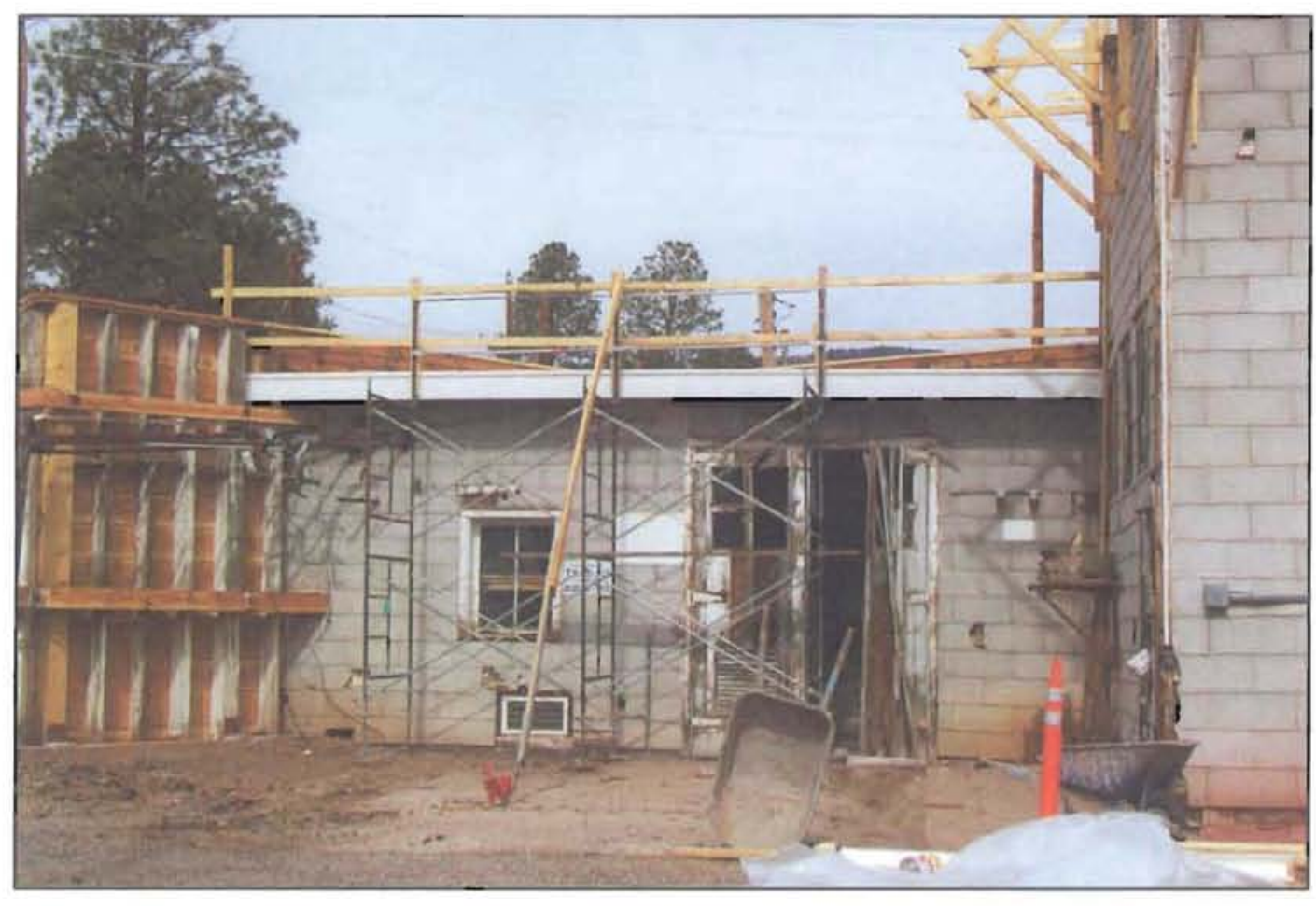

- Los Alamos NATIONAL LABORATORY

The World's Greatest Science Protecting America

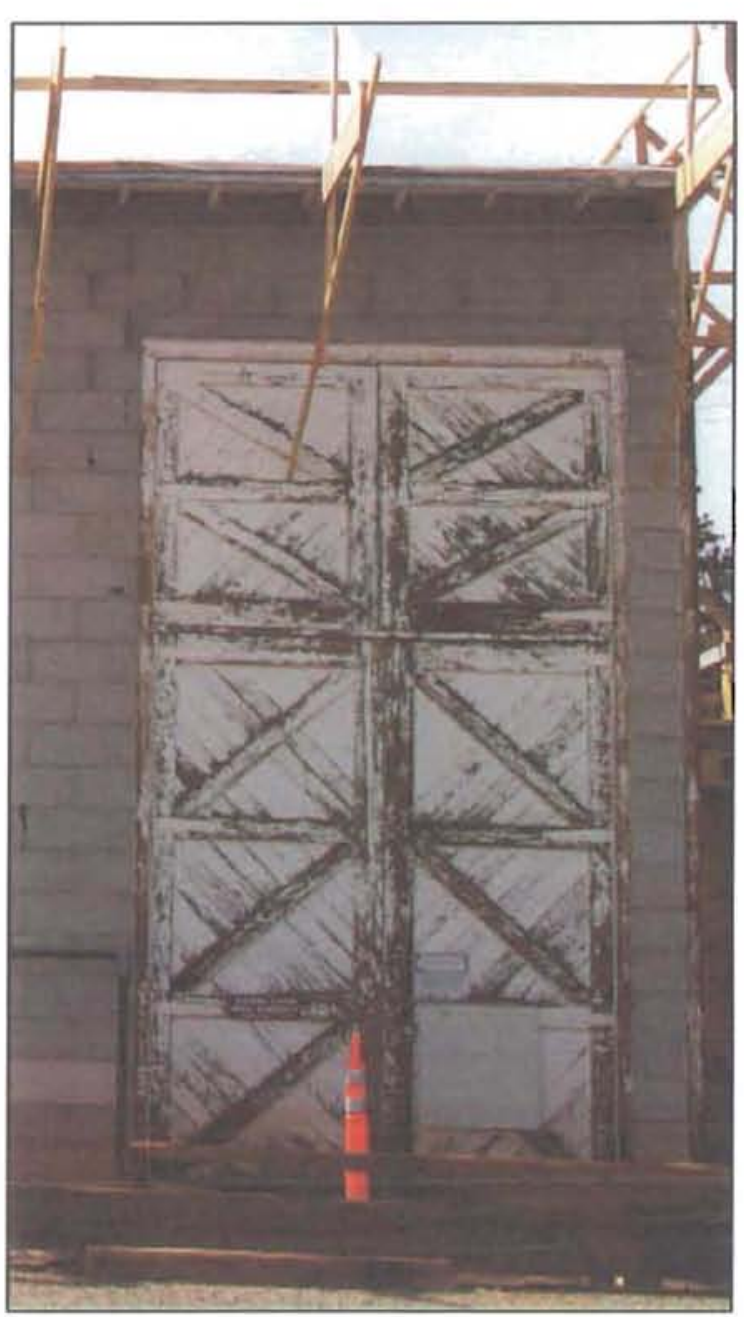

UNCLASSIFIED

NAS 


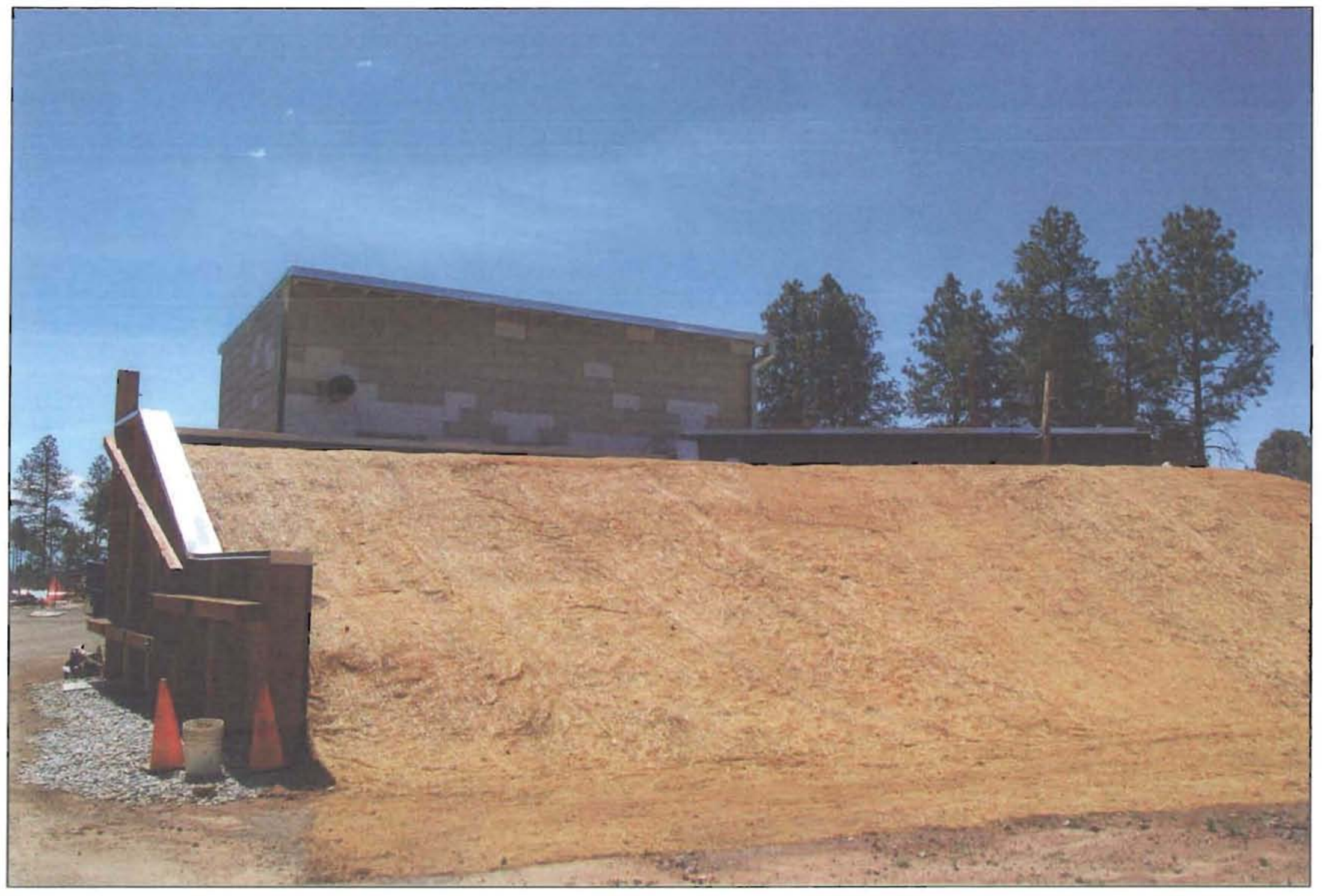

\section{Los Alamos}




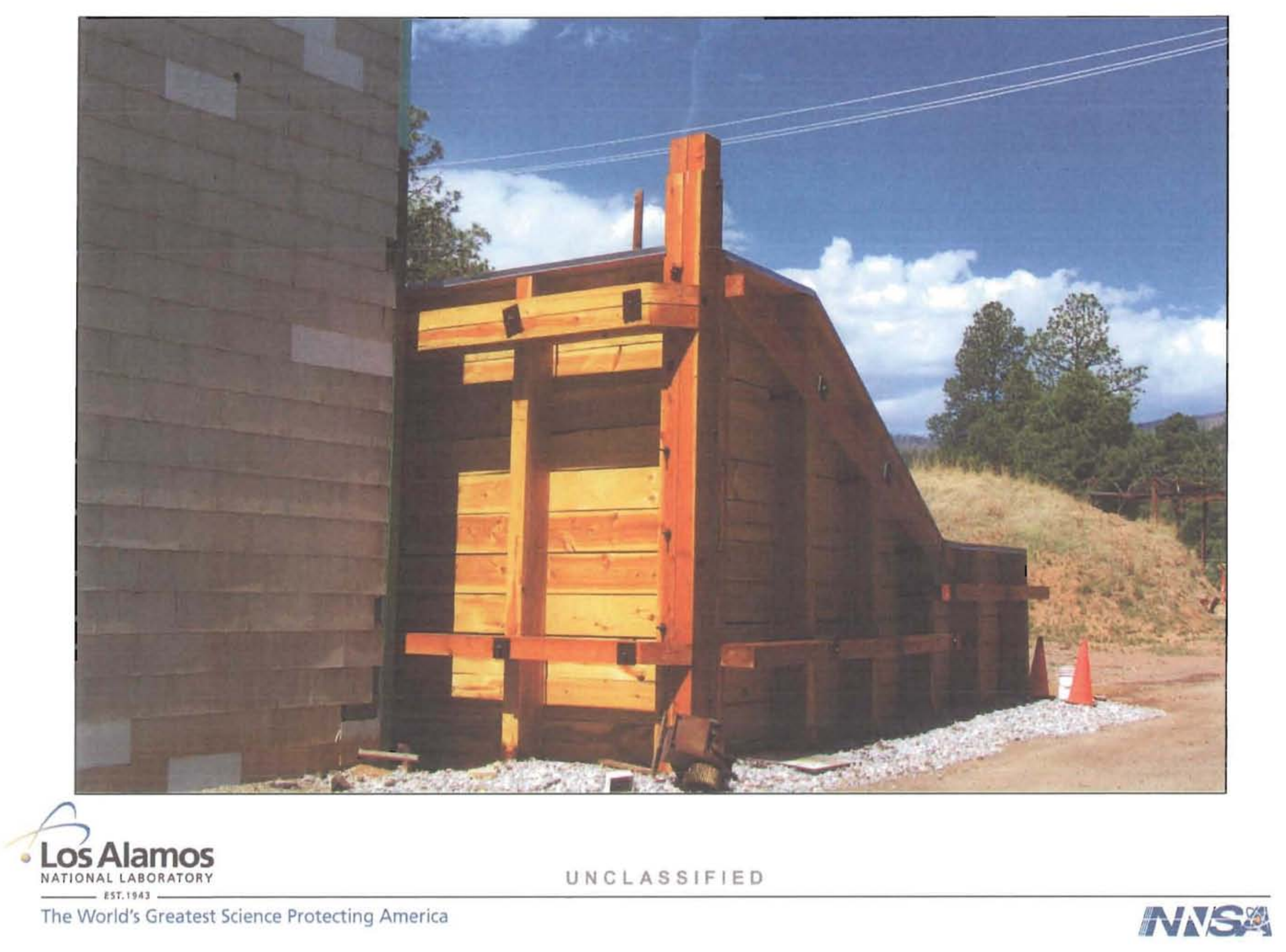




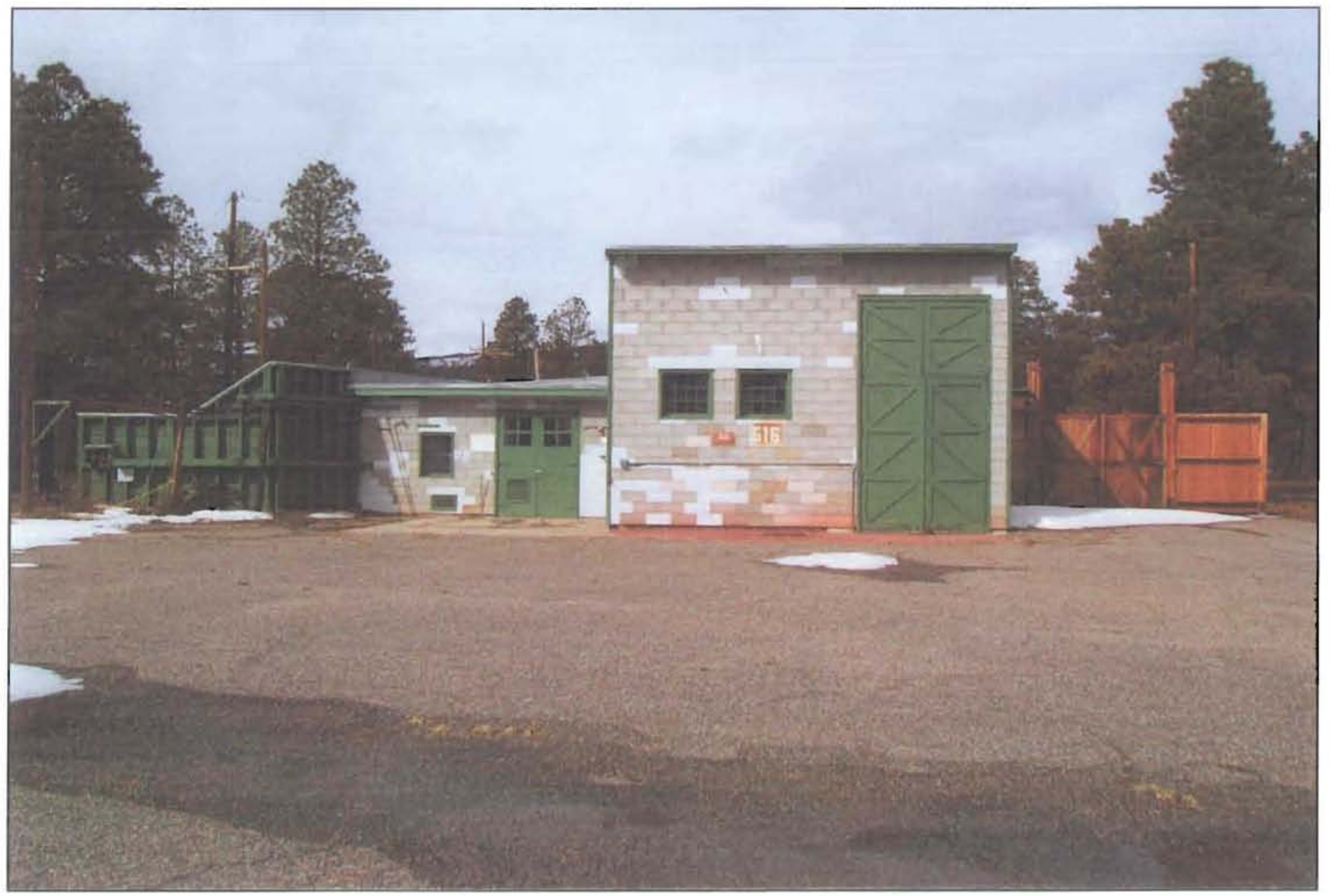

Los Alamos 


\section{Questions? Comments?}

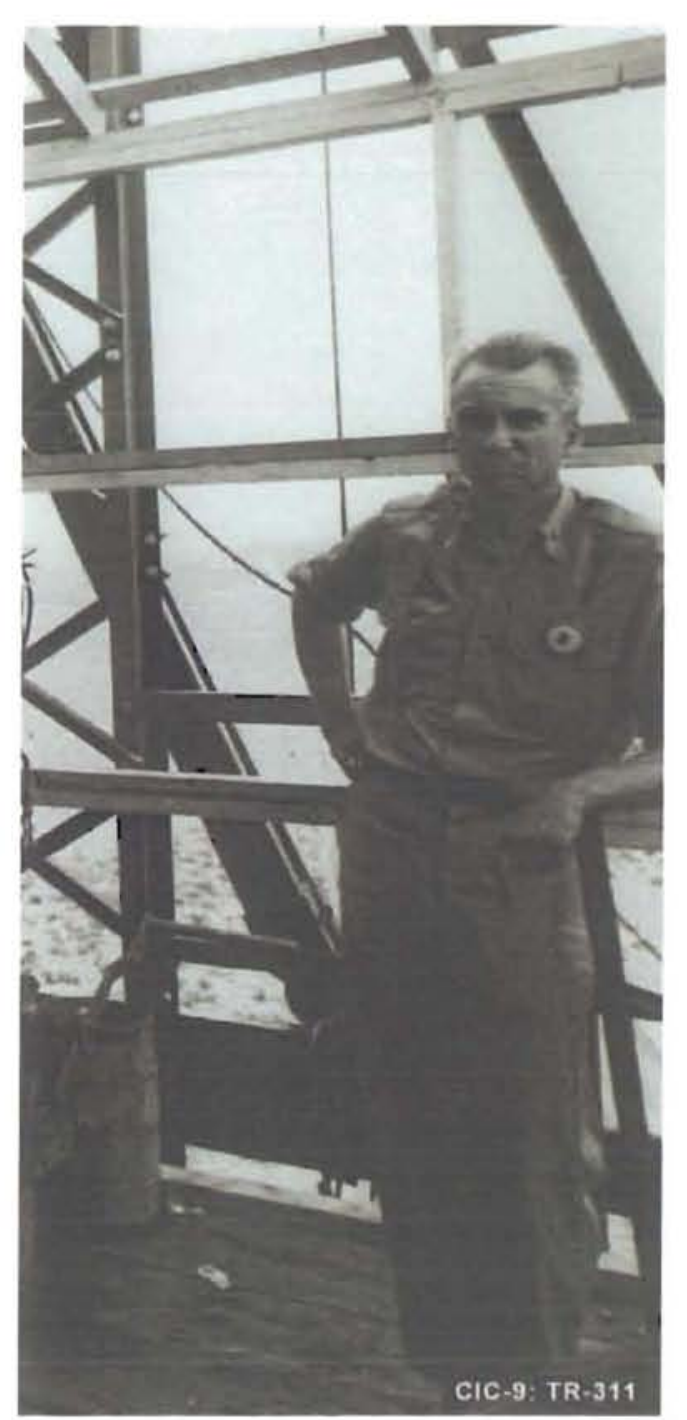

- LOS Alamos

UNCLASSIFIED

The World's Greatest Science Protecting America

NAS 